\title{
A Review on Bio-inspired Synthesis of Silver Nanoparticles: Their Antimicrobial Efficacy and Toxicity
}

\author{
S.R. Prasad, ${ }^{1}$ S. B. Teli, ${ }^{2}$ J. Ghosh, ${ }^{3}$ N.R. Prasad, ${ }^{4}$ V. S. Shaikh,,${ }^{5}$ G.M. Nazeruddin, ${ }^{6}$ Abdullah G. Al-Sehemi, ${ }^{7}$ Imran Patel ${ }^{8}$
} and Y. I. Shaikh ${ }^{6, *}$

\begin{abstract}
Silver nanoparticles are one of the most studied compounds in materials science due to their antimicrobial efficacies and, for instance, in photocatalysis, dye-sensitised solar cells, and biomedical devices. However, conventional methods of synthesis of silver nanoparticles (AgNPs) require hazardous and costly chemicals, and a large amount of energy is expended. In this review, efforts have been made to target where eco-friendly synthetic techniques are being conducted using various plant extract to develop nanoparticles in inexpensive, easily scaled up, and environmentally benign. These findings are stimulated intense research activities that focused on synthesis, modification, properties, and applications of these ecofriendly nanoparticles. This review covers all these aspects, such as the biological routes for the synthesis of nanoparticles employed to synthesis the nano-silver using algae, bacteria, plants, fungi, etc. Also, the chemical positions and possible traditional uses of the plants are enlisted.
\end{abstract}

Keywords: Silver Nanoparticles; Plant Extracts; Green Synthesis; Antimicrobial Activity; Hazardous Effects and microorganisms. Received: 29 March 2021; Accepted: 30 June 2021.

Article type: Review article.

\section{Introduction}

It is a well-known concept that inert and living matters consist of atoms. Nevertheless, in practice, this knowledge does not affect everyday life. An atom is so tiny that it is beyond our perception. Although the general progress of physical, chemical, and biological sciences clearly appreciates the atomic nature of matter, real-life could ignore the elementary bricks we are made up of. However, at the end of the $20^{\text {th }}$ century, with the breakthrough of nanotechnology, it can be

\footnotetext{
${ }^{1}$ DKTE College of Engineering, Ichalkaranji-416115 (MH), India

${ }^{2}$ Department of Industrial Chemistry, Shivaji University, Kolhapur416008 (MH), India.

${ }^{3}$ Smt. Kasturbai Walchand College, Sangli-416416 (MH), India.

${ }^{4}$ School of Nanoscience and Technology, Shivaji University, Kolhapur-416008 (MH), India.

${ }^{5}$ National Chemical Laboratory (NCL), Pashan, Pune- 411008 (MH), India.

${ }^{6}$ Department of Chemistry, Abeda Inamdar Senior College, Pune411001 (MH), India.

${ }^{7}$ Department of Chemistry, King Khalid University, Abha-61413, Saudi Arabia.

${ }^{8}$ Post Graduate Research Centre in Zoology, Modern College of Arts, Science and Commerce, Shivajinagar, Pune.

*Email: sheray2k@gmail.com (Y. I. Shaikh)
}

realised that the nonmetric size, close to that of atoms, was no longer beyond our perception and "Nanos" are now guests of our everyday life. ${ }^{[1]}$ A bulk material has constant physical properties regardless of its size and shape, but at the nanoscale often this is not true. Several well-characterised bulk materials have been found to possess the most exciting properties studied at the nanoscale range. The dimensions of these particles indicate a high surface area to volume ratio that shares enhanced chemical activity, high surface plasmon resonance, enhanced Rayleigh scattering and surface enriched Raman scattering compared to their bulk material. Many more nanoparticle applications such as signal reporters to detect various biomolecules in immunoassay, as fluorophore in fluorescence in situ hybridisation, cell bioimaging, an antioxidant to remove free radicals from the patient bloodstream, delivering vaccines and drugs, treating infectious diseases, detection of cancer, fabrication of scaffolds and also more importantly in bioremediation. ${ }^{[2-3]}$ and further details of usage of nanoparticles are mentioned in Fig. 1.

Nanoparticles are of great scientific interest as they bridge the gap between bulk materials and atomic and molecular structure. Metallic nanoparticles are intensely studied due to their unique optical, electrical, and catalytic properties. To utilise and optimise the nanosized various metal-oriented 


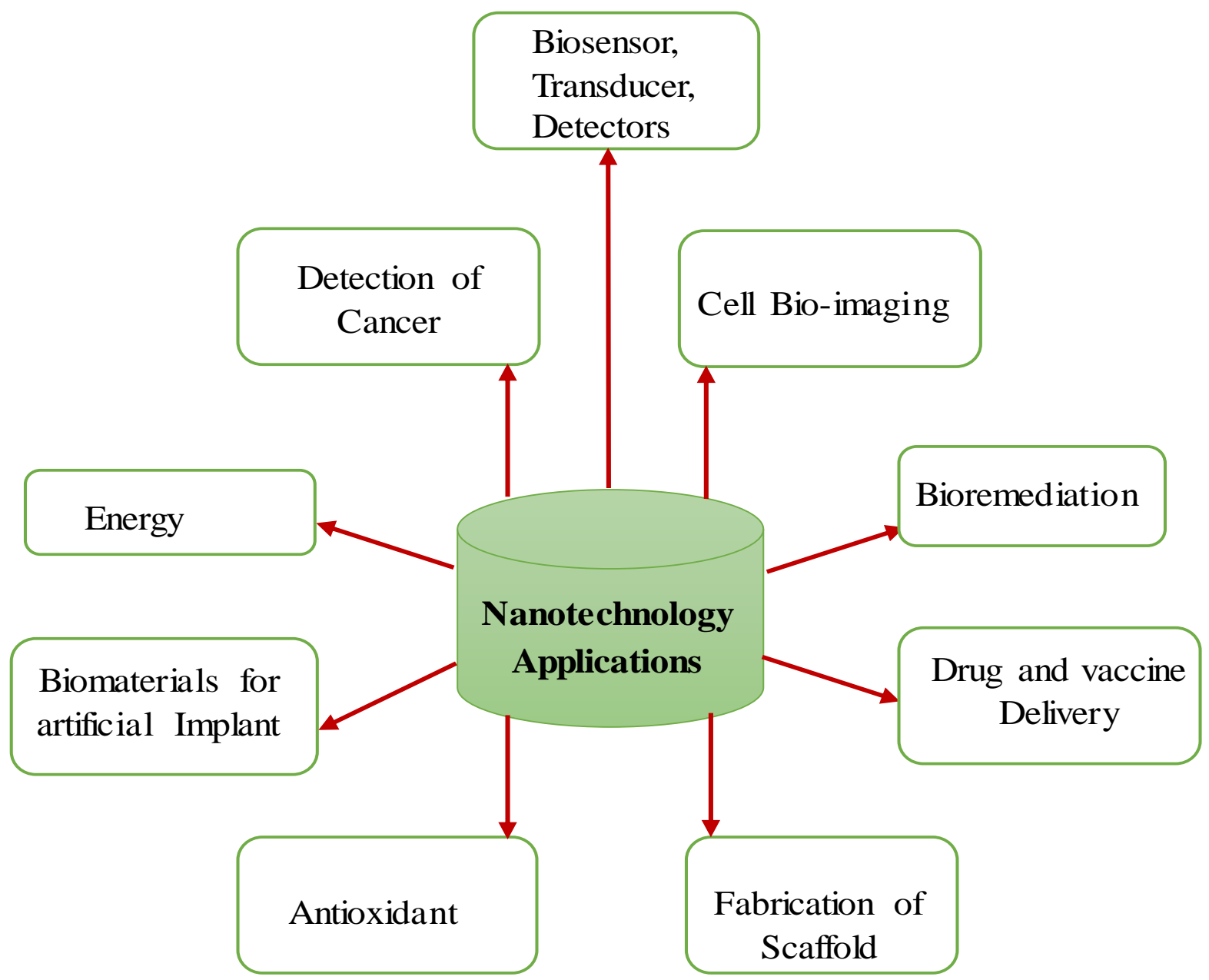

Fig. 1 Applications of nanotechnology in various areas.

nanoparticles, chemical and physical properties, a large spectrum of research has been focused on controlling the size and shape, which is crucial in tuning their properties. Recently there has been considerable interest in developing techniques for controlled synthesis of metal nanoparticles of well-defined shape, size, and composition as they exhibit biocompatibility and find applications in electronics, catalysis, biomedical and optics areas. ${ }^{[2,4]}$

1.1 Nature: The source of inspiration for nanotechnologists The concept of developing or synthesising material at the nanoscale range of nanostructures is one of the researcher's fundamental interests. Nature itself is a powerful source of inspiration for nanomaterial synthesis. For example, leaves of the Lotus plant (Nelumbo nucifera) have a self-cleaning property. That property exhibited by some nanoparticles embedded in its moiety, so much so that the self-cleaning effect is often claimed as the "Lotus effect". The Lotus plant is considered a symbol of purity in China for more than 2,000 years since it emerges from swamps and exists in filthy environments but still keeps its leaves free of all the dirt around it.

Nature is engrossed in bio-conversion of splendid biomass using complicated biochemical pathways. Biochemical and material scientists struggled to elucidate the complexity of nature's network in their laboratory. ${ }^{[5-6]}$ Mother Nature is the most efficient architect of highly specialised materials, which are, of course, engineered by nature herself to exert specific biological functions. ${ }^{[7]}$ During evolution, nature has ingeniously created an impressive variety of inorganic crystals. Scientists and engineers have always been fascinated by the marvellous structures and functional properties of materials within the living system. How a biological system fabricates and reproduces structural and functional inorganic materials with precise dimensions and controlled morphology has attracted nanotechnologists. The intricacies and the functional efficacies of the biological world fascinate both scientists and ordinary person. From a materials scientists' point of view, the formation of the appealing siliceous structures of the diatoms, calcareous structures produced by the haptophytes, and the aligned magnetic nanoparticles synthesised by the magnetotactic bacteria are very inspirational. ${ }^{[8]}$

To fabricate the inorganic materials using biological process, nature's elegant architectural skills and precision inspire a lot. Material scientists are trying to learn from nature to develop new synthetic materials with sophisticated properties. Bio-mimetic is an art and science to adapt the constructional principles from engineering, chemistry, and 
biology are investing in the synthesis of natural materials or technologies that have purposes that mimic biological methods. Inspiration from natural bioinorganic structures has laid the foundations of this very science. Also, material scientists are trying to fabricate nanostructure with the precision of nature's flawless architectural skills that are pretty ahead of present anthropogenic capacities. Most of the work in this direction has been carried out to synthesis of nanomaterials with complex morphologies. ${ }^{\left[{ }^{[9}\right.}$

\subsection{Synthetic routes of nanoparticles}

Several approaches in practice to generate metallic nanoparticles, such as UV-radiation, aerosol technology, lithography, laser ablation, ultrasonic fields, and photochemical reduction techniques. Meanwhile, different nanoparticle synthesis methods can be mentioned as electrochemical, sonochemical, and microwave-assisted processes. ${ }^{\left[{ }^{[10]}\right.}$ The chemical method is the traditional and most commonly used method for the synthesis of nanoparticles. In most cases, the chemical synthesis methods lead to some chemically toxic substance adsorbed on the surface, hindering their usages in medical applications. Many studies have revealed that potent reducing agents such as borohydride and hydrazine hydrate resulted in tiny particles that were somewhat mono-disperse. However, the generation of larger particles was challenging to control. The use of weaker reducing agents such as citrate resulted in a slower reduction rate. However, these methods carry the disadvantages of being expensive, high energy utilisation, difficulty in purification, and use of hazardous

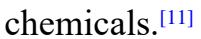

The methods of synthesis of nanoparticles can generally involve either a top-down approach or a bottom-up approach. In top-down synthesis, nanoparticles are produced by size reduction from a suitable starting material. However, size reduction is achieved by various physical (mechanical) and chemical treatment expense is very high. A further drawback of "physical" approaches is the enormous consumption of energy to maintain the high temperature and pressure used in the synthesis procedure. In contrast, most bioprocesses occur under normal air pressure and temperature, resulting in vast energy savings. In addition, top-down production methods introduce imperfections in the surface structure of the product. This is the major limitation because the surface chemistry and other physical properties of nanoparticles are highly dependent on the surface structure.

In the bottom-up, approach nanoparticles are built from smaller entities, for example, by joining atoms, molecules, and smaller particles. In bottom-up synthesis, the nanoparticles are formed first and then assemble to form the final particle. The bottom-up synthesis mainly relies on chemical and biological methods of production. The traditional and most widely used methods for the synthesis of metallic nanoparticles use wet chemical procedures. A typical procedure involves growing nanoparticles in a liquid medium containing various reactors, particularly reducing agents (e.g. sodium borohydride or potassium bitartrate or methoxy polyethylene glycol or hydrazine). A stabilising agent such as sodium dodecyl benzyl sulfate or polyvinyl pyrrolidane is also added to this reaction mixture to arrest the agglomeration of metallic nanoparticles. Generally, the chemical methods are of low cost for high volume; however, their drawback includes contamination from precursor chemicals, use of toxic solvents, and generation of hazardous by-products. The synthesis of nanoparticles can also be classified in different ways as given below methods; Figs. 2(a, b, c, d) indicates the different methods for synthesis nanoparticles.

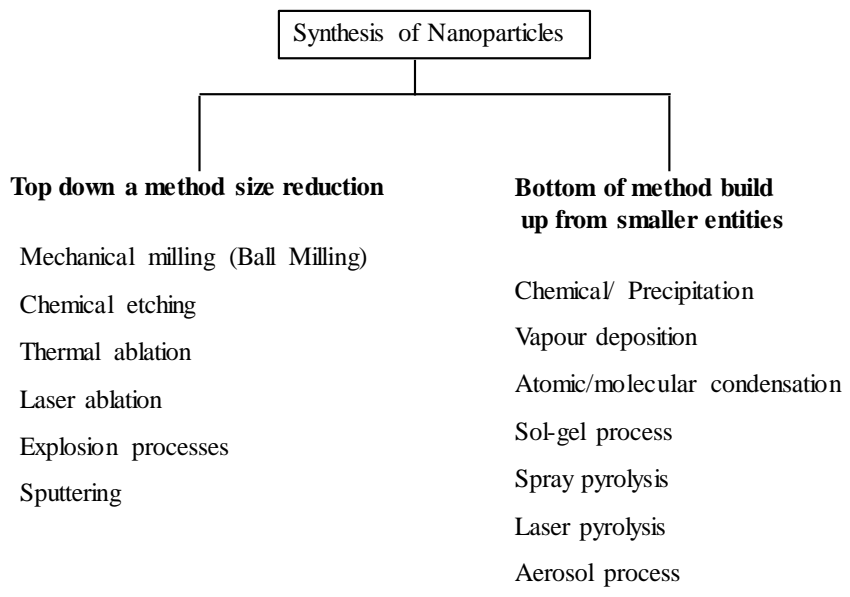

Fig. 2(a) Methods for nanoparticles synthesis.

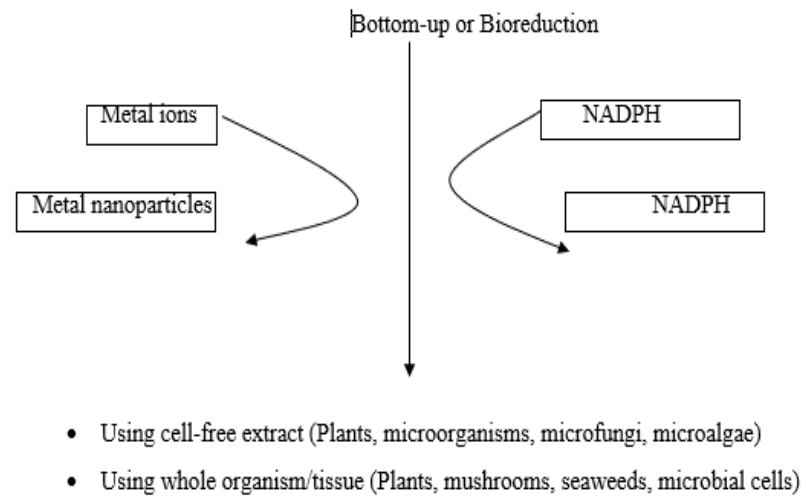

Fig. 2(b) Methods for nanoparticles synthesis.

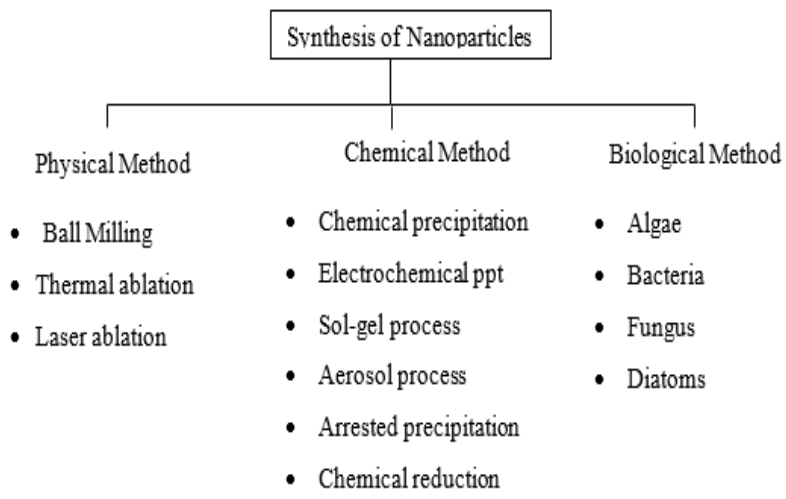

Fig. 2(c) Methods for nanoparticles synthesis. 


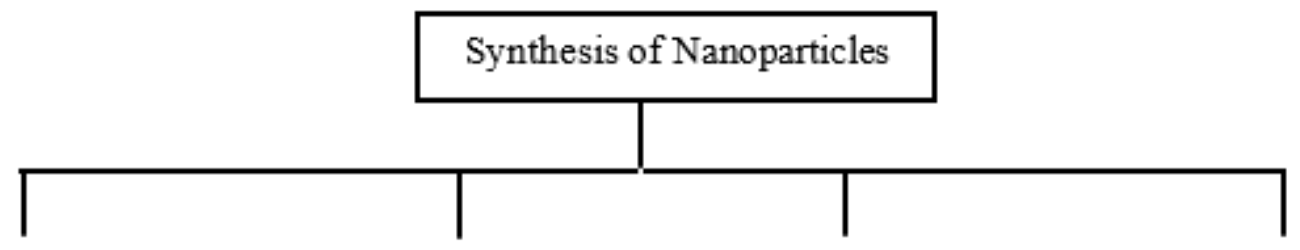

a) Wet Solution

- Sol-gel

- Co-precipitation b) Template

- Porous alumina membrane

- Track etched membrane c) Gas Phase Method

- Thermal evaporation

- Hot walled reactor

- MWCVD reactor

- ECR MW reactor

- Fluidized plasma bed reactor

- RF plasma reactor

- Hot filament CVD

- Hot filament grid

- MBE (Molecular beam epitaxy)

- Laser evaporation

- E-beam lithography

- FIB d) Biological Method

- Nano gmprinter

- DPN

- Ball milling

- STP tip assembly

Fig. 2(d) Methods for nanoparticles synthesis.

- Using cell-free extract (Plants, microorganisms, microfungi, microalgae)

- Using whole organism/tissue (Plants, mushrooms, seaweeds, microbial cells)

On the other hand, the practice of toxic chemicals on the surface of nanoparticles and non-polar solvents in the synthesis procedure limits its tender in clinical fields. Therefore, the development of clean biocompatible, non-toxic and eco-friendly methods is regarded as a safe, cost-effective, sustainable, and environment-friendly process; they also have some drawbacks in culturing microbes. It is time-consuming and challenging to provide better control of size distribution shape and crystallinity. The biological nanoparticles are not mono dispersible, and the rate of production is slow. These are the problem that has plagued biological synthesis approaches. ${ }^{[12]}$ Since the development of nanotechnology, many approaches for nanoparticle synthesis have been discovered and improved. These are chemical methods based on hazardous chemicals, enormous energy, and high temperature and form nanoparticles with limited properties. Generally, the green synthesis method that has progressed recently is based on biological sources such as plants, microorganisms, and industrial and agricultural wastes. Biological synthesis has been applied mainly in nanoparticle production and has also been used for fabricating bimetallic or trimetallic alloy nanoparticles. It has provided advancement over another process as it is simple, cost-effective, and relatively reproducible, and often results in more stable materials. Microorganisms can be employed to produce nanoparticles, but the synthesis rate is slow. The only limited number of sizes and shapes are amenable compared to routes involved in plant-based materials. At present condition, the fungus is gaining worldwide popularity as "Nano Factories" to synthesise nanoparticles. Extracellular or intracellular extract of fungi is a perfect applicant for synthesising metal nanoparticles due to the scalability and cost-efficiency of fungal growth, even on an industrial scale. ${ }^{[13]}$ Overall, biological materials provide an environmentally friendly or greener chemical method to produce valuable materials because the biomaterials-based routes eliminate the need to use harsh and toxic chemicals. ${ }^{[14-15]}$ Recently, Molnar et al. synthesised gold nanoparticles by thermophilic filamentous fungi. The exact process was applied to produce Silver nanoparticles using the fungus Aspergillus flavus and numerous reports are reported. ${ }^{[16]}$ Also, fungi can be easily cultivated on a large scale ("nanofactories") and can synthesis nanoparticles with controlled size and morphology. Fungi have advantages over other microorganisms in that they produce large quantities of proteins and enzymes that can be used for the wild and viable production of nanoparticles. ${ }^{[16]}$

To switch over these technical hitches, biological principles have been established recently. The technique for obtaining nanoparticles uses naturally occurring reagents such as vitamins, sugars, plant extracts, biodegradable polymers, 
and microorganisms like diatoms, fungi, bacteria, viruses, etc., or mimicking biological systems. The biomolecules isolated from them act as reductants and stabilising agents that could be considered attractive for nanotechnology. So far, nanoparticles have been synthesized by various biological routes, and Table 1 summarises the earlier work done by various researchers. ${ }^{[14,17-21]}$ It is unavoidable that the silver nanoparticles are synthesized have to be handled by humans and must be available at cheaper rates for their effective utilisation; thus, there is a need for an environmentally and economically feasible way to synthesise them. The quest for such a method has led to the need for bio-mimetic production of silver nanoparticles, whereby biological methods are used to synthesise the silver nanoparticles. ${ }^{[22-23]}$

\subsection{Bio-fabrication of metallic nanomaterials}

Fabrication of metal, metal oxides, and salt nanoparticles using natural substances is an up-and-coming area in nanotechnology, which came to prominence only a few years ago. Valuable materials can be produced quickly, even on a reasonable scale, because the biomaterial-based routes eliminate the need to use harsh and toxic chemicals. The majority of green synthetic efforts reported so far are dedicated to obtaining silver nanoparticles, perhaps due to their importance as disinfectants, ease of preparation, and utility in several applications. Silver nanoparticles can be produced either intra or extra-cellularly by using living organisms. ${ }^{[24]}$ Similar reports are available to synthesise gold nanoparticles of uniform size extra-cellularly using extremophilic actinomycete Thermomonospora sp. ${ }^{[25]}$ Synthesis of inorganic nanomaterial can be carried out by using different biomolecules. The mineral deposition in the biological organism controlling the nucleation and growth of inorganic structure is regulated by proteins or other biological macromolecules found in the organic matrix. The realisation of this fact has led to material scientists exploring and identifying enzymes as bio-mineralising agents capable of in vitro material synthesis. In such systematic attempts, limited success has been achieved in synthesising inorganic nanoparticles with specific compositions, sizes, and shapes. Since proteins are known to initiate, catalyse and fabricate nanostructures, attempts have been made to synthesise various nanostructures using proteins isolated from bio-minerals, e.g., silica formation by silicates, silafins, and silica precipitating peptides. ${ }^{[26-27]}$

Furthermore, bacterial cell surface, virus, proteins, small peptides, and even pollen grains have been widely employed to synthesise nanostructures with various compositions, sizes, and shapes. Bio-polymers are used as frameworks for forming inorganic structures such as calcium carbonates, hydroxyapatite, iron oxide, and silica materials. DNA, the carrier of genetic information in all living organisms, is also a versatile material for designing nanometer-scale structures. DNA can be used as an ideal template for synthesising nanoparticles due to some key features such as inherent nanoscale dimensions, high specificity exerted towards inorganic materials, and structural flexibility to build nanoparticles of different sizes and shapes. ${ }^{[28]}$

There are three primary biological sources of synthesising silver nanoparticles: bacteria, fungi, and plant extracts. Biosynthesis of silver nanoparticles can be classified as a bottom-up approach that mainly involves redox reactions. The biological method used to synthesise nanoparticles may be based on either microbial enzyme or plant phytochemicals with antioxidant properties that act on respective precursors and synthesise the desired nanoparticles. The biological method fulfils all three essential requirements of preparing nanoparticles viz. solvent medium (for synthesis), the environmentally friendly reducing agent, and non-toxic stabilising agents. ${ }^{[29-33]}$

The binding of green chemistry to nanotechnology is one of the critical issues in nanotechnology research. There are some species of algae that are used as bio-factory for the synthesis of metallic nanoparticles. Recently, Shahverd. et al. have synthesised the noble metallic nanoparticles by culture supernatant of Klebsiella pneumonia. ${ }^{[34]}$ Green synthesis of metallic nanoparticles as effective alternatives to treat antibiotics resistant bacterial infections, NPs interact with the essential cellular organelles and biomolecules like DNA, enzymes, ribosomes, and lysosomes that can affect cell membrane permeability, oxidative stress, gene expression, protein activation, and enzyme activation. ${ }^{[35]}$ Also, fungus such as Verticillium, Fumigatus, Trichoderma, Asperellium, Phapnerochaete Chrysosporium has been explored for noble metallic nanoparticle synthesis. ${ }^{[36]}$ Similarly, Beveridge and co-workers have demonstrated the deposition of gold nanoparticles within bacterial cells. ${ }^{[37]}$ Silver-based crystalline nanoparticles, microbially fabricated by microbial, are used to reduce $\mathrm{Ag}^{+}$ions. The formation of silver nanoparticles within the periplasmic space of the bacterium Pseudomonas stutzeri (AG259) was used shown by Klaus and his team. ${ }^{[38]}$

Numerous reports have been published in the literature related to various aspects of bio-mineralisation. Furthermore, the synthesis of metal nanoparticles using plants is being looked into with interest. While microorganisms continue to be investigated for bio-mineralisation and metal nanoparticle synthesis, the use of plant extracts in similar nanoparticle biosynthesis methodologies is an exciting possibility and is relatively unexplored and under-exploited. Among the different methods used for metallic nanoparticle synthesis, bio-synthesis using plants is of particular interest because they are environmentally benign and require shorter synthesis time than the elaborate process of maintaining cell culture required in microorganism-assisted synthesis. Green methods involving plant materials that have been used in nanoparticle synthesis are generally single pot reactions, without the use of additional surfactants, capping agents, and templates. Frequently the technique developed for a given metal and metal oxide nanoparticles could also be applied for other metals. ${ }^{[39]}$ 
Table 1. Synthesis of metallic nanoparticles by different biological routes.

\begin{tabular}{|c|c|c|c|c|c|c|c|c|}
\hline Medium & $\begin{array}{c}\text { Type of } \\
\text { nanoparticle } \\
\text { s }\end{array}$ & $\begin{array}{l}\text { Location/ } \\
\text { Shape }\end{array}$ & $\begin{array}{l}\text { Active Plant } \\
\text { Components }\end{array}$ & Bio- & $\begin{array}{l}\text { size range } \\
\text { (in } \mathrm{nm} \text { ) }\end{array}$ & $\begin{array}{l}\text { Ayurvedic \& } \\
\text { Medicinal Uses }\end{array}$ & Unani & Reference \\
\hline
\end{tabular}

(A)

Algae

Sargassum wightii

Chlorella vulgaris

(B)

Bacteria

Pseudomonas stutzeri

Morginella sp

Lactobacillus strain

Plectoma baryanum

Escheria coli
Ag Intracellular

Ag Extracellular

$\mathrm{Ag}$ and

$\mathrm{Au}$

Intracellular

CdS Intracellular
Sulphates,

polysaccharide,

phenolics,

plastoquinone,

phlorotannins,

fucoxanthin,

fucoidan, sargaquinoic

acid, sargachromenol,

steroids, terpenoids, and

flavonoids.

Dired mass contains

$45 \%$ protein, $20 \%$

carbohydrates, $\quad 20 \%$

fats, $10 \%$ minerals and

vitamins and $5 \%$ fibers.
8-12

9-20

It is used as an antibiotic and peritoneal dialysis

Analgesic, antiinflammatory,

antioxidant,

neuroprotective, antimicrobial, anti-tumor, fibrinolytic, immunemodulatory, anticoagulant,

hepatoprotective, antiviral activity, etc.

It can ameliorate hyperlipidemia and hyperglycemia, and protect against oxidative stress, cancer and chronic obstructive pulmonary disease.

Lactobacillus is taken by mouth for skin disorders such as fever blisters, canker sores, and acne. It is also used to treat or prevent eczema (allergic dermatitis), sensitivity to sun exposure (polymorphous light eruption), sensitivity to environmental allergens, and hay fever in infants and children.

$1-10$

In recent years, E. coli have been used to make important antibiotics, produce cancer-fighting drugs, and even manufacture insulin. $E$.

67

coli is known for being 


\section{Clostridium}

thermocetium

Actinobacter spp.

Shewanella algae
Magnetite

Extracellular

Intracellular@

$\mathrm{pH}=7 \quad \&$

Extracellular

$@ \mathrm{pH}=1$
$10-40$ easy to manipulate on a genetic level-the bacterium's cells readily accept tweaks that more complicated organisms might resist.

Clostridium contains around 250 species that include common freeliving bacteria, as well as important pathogens. Clostridium perfringens causes a wide range of symptoms, from food poisoning to cellulitis, fasciitis, necrotic enteritis and gas gangrene. Clostridium tetani causes tetanus.

Acinetobacter baumannii can cause infections in the blood, urinary tract, and lungs (pneumonia), or in wounds in other parts of the body. It can also "colonize" or live in a patient without causing infections or symptoms, especially in respiratory secretions (sputum) or open wounds.

Until the early nineties, the genus Shewanella was clinically associated with human infections with the species designation of S.putrefaciens. However, Nozue et al., differentiated the genus into S.putrefaciens and S.algae based on $\mathrm{mol} \% \mathrm{G}+\mathrm{C}$ content and biochemical properties. Since the description of first human infection by S.algae, more than $90 \%$ strains of S.algae were reported as human pathogens. Nath $e t$ al. from India reported two cases of gastroenteritis where S.algae was isolated from the rectal swab. Similarly Gautam et $a l$, recorded first case 


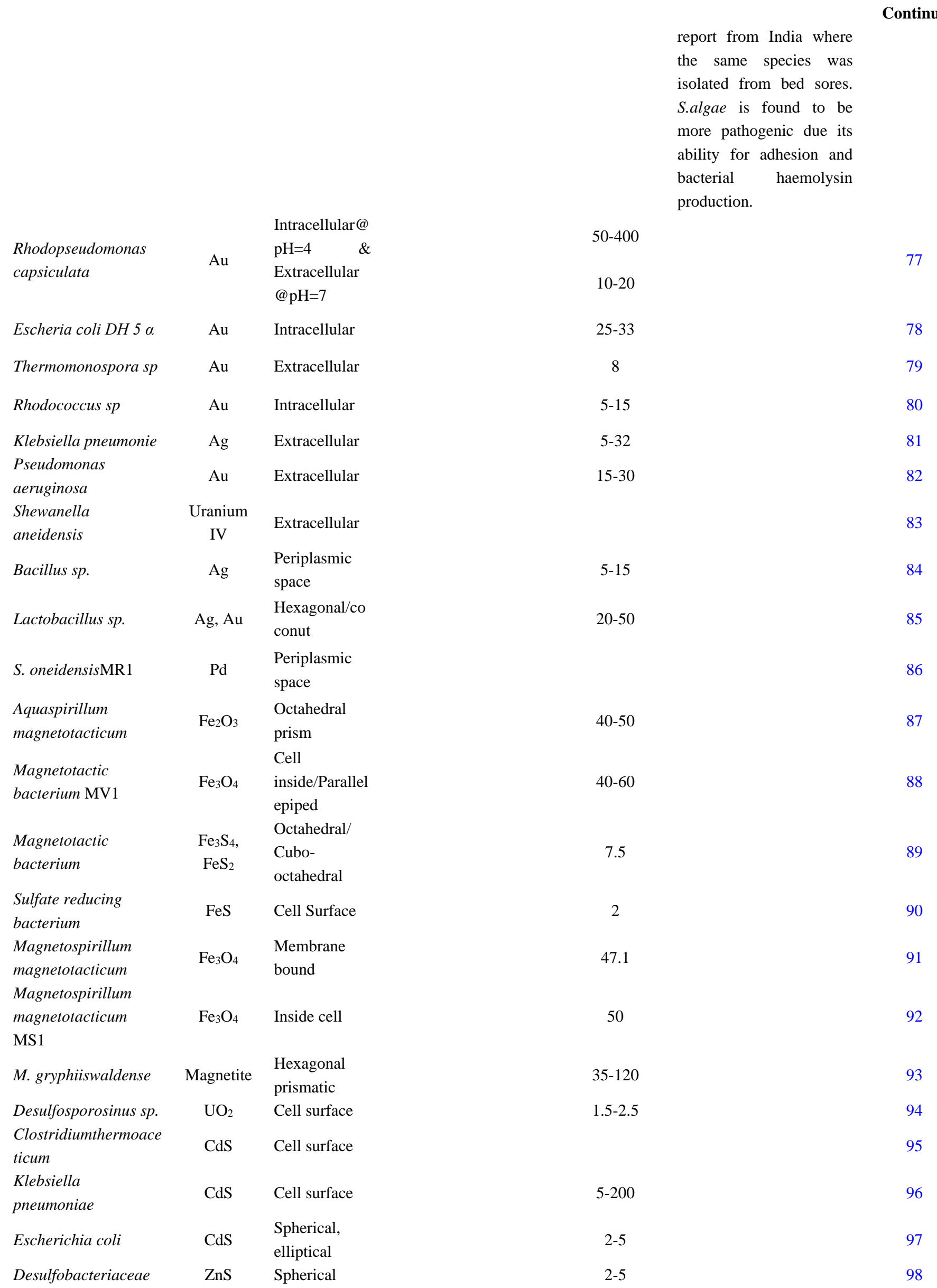




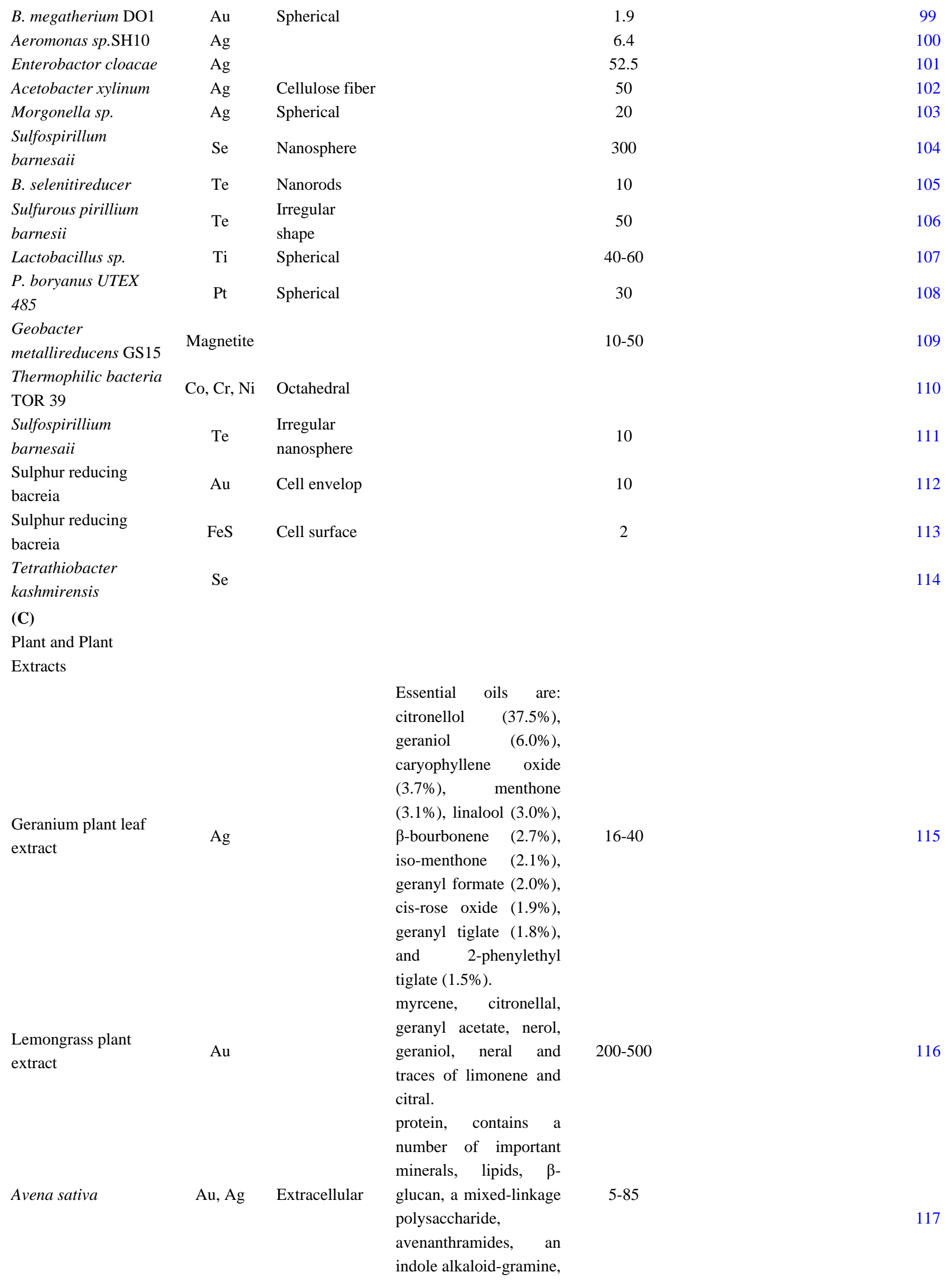




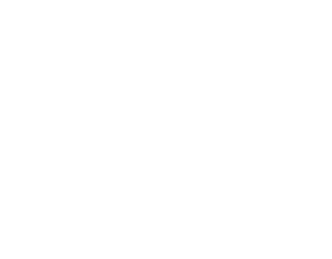

Cinnamon camphora

Au \& Ag Extracellular

$\mathrm{Au} \& \mathrm{Ag}$

Azadirachta indica

Bimetallic

Artocarpus

heterophylus seed

Ag

69.39\% Carbohydrate, $13.67 \%$ protein, $10.78 \%$ moisture, $2.41 \%$ ash, $0.75 \%$ fat and $3.00 \%$ crude fiber.

$\delta$-Cadinene $(9.6 \%), \alpha$ epi-cadinol $\quad(7.38 \%)$, pulegone (5.95\%),

Jatropa curcas

flavonoids,

flavonolignans,

triterpenoid saponins, sterols, and tocols.

D-camphor (40.54\%),

linalool (22.92\%),

cineole (11.26\%), and

3,7,11-trimethyl-3-

dodecadien-1-yl acetate

(4.50\%).

isomeldenin, nimbin,

nimbinene, 6-

desacetyllnimbinene,

nimbandiol, immobile,

nimocinol, quercetin,

and beta-sitosterol. Two

additional tetracyclic

triterpenoids zafaral

[24,25,26,27-

Tetranorapotirucalla-

(apoeupha)-6alpha-

methoxy-7alpha-

dione-21-al] (1) and

meliacinanhydride

$[24,25,26,27-$

tetranorapotirucalla-

(apoeupha)-6alpha-

hydroxy,11alpha-

methoxy-

7alpha,12alpha-

diacetoxy, 1,14,20(22)-

trien-3-one].

chrysanthenyl acetate
55-80

118

50-100

119

(5.26\%), $\quad \alpha$-cadinol

(4.32\%), thymol

(4.03\%).

\section{Continued}




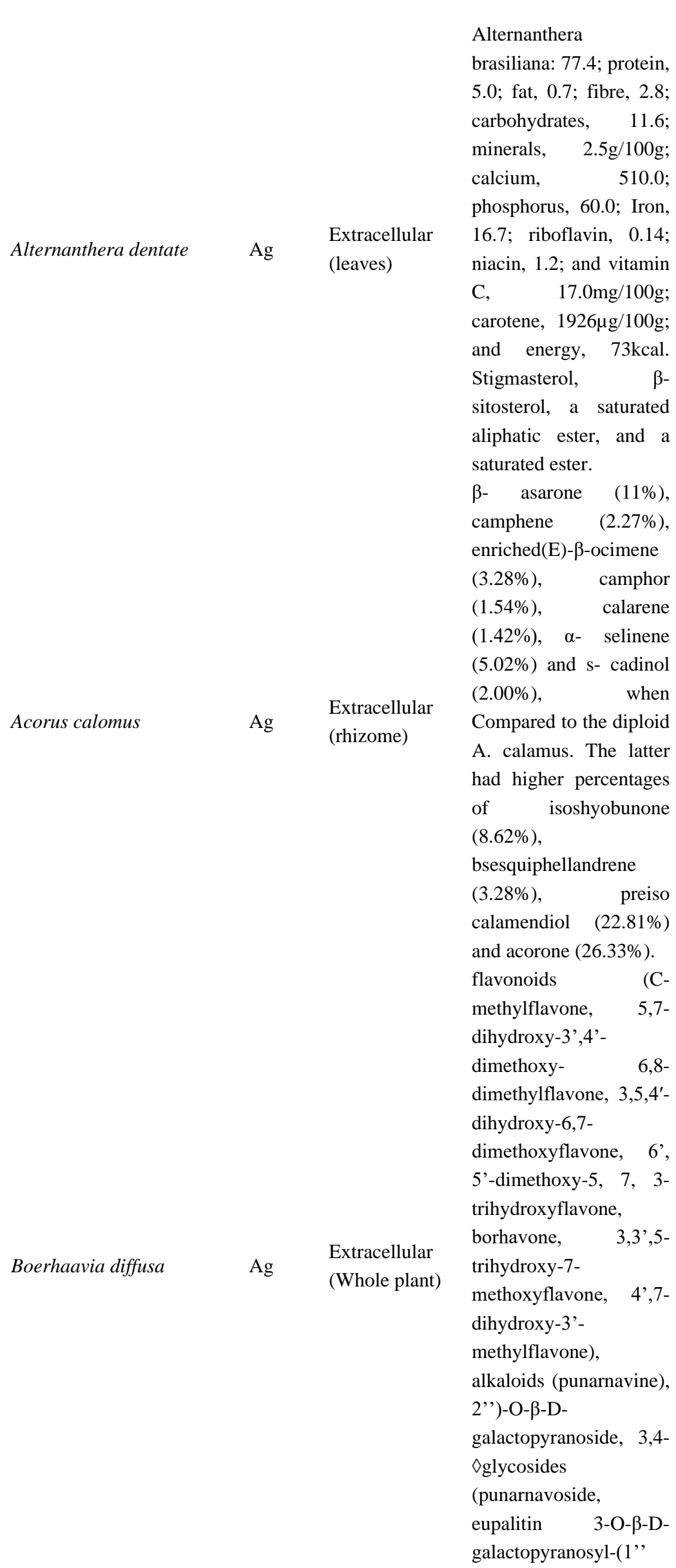

50-100

It is often harvested from the wild for regional use as a food and medicine, where it is used as an antiviral and antidiarrhoea agent.

The plant is found to have potent anti-oxidant anti-ulcer, anti-diabetic, anti-microbial, wound-healing, radioprotective, pesticidal and insecticidal properties. It is also neuroprotective, reduces cardiovascular complications, and even helps in phytoremediation of the environment. It has also been found that $\mathrm{A}$. calamus reduces the stress-induced suppression of immunity.

Boerhaavia diffusa is an herb found in Ayurveda and other traditional medicines. Historically, Boerhaavia diffusa has been used for its antidiabetic and diuretic properties. In different areas of the world, Boerhaavia diffusa has also been used for pain relief, anti-inflammation, and treating indigestion. Boerhaavia diffusa is a tropical crawling root plant, with bioactive compounds in both the leaves and roots. 


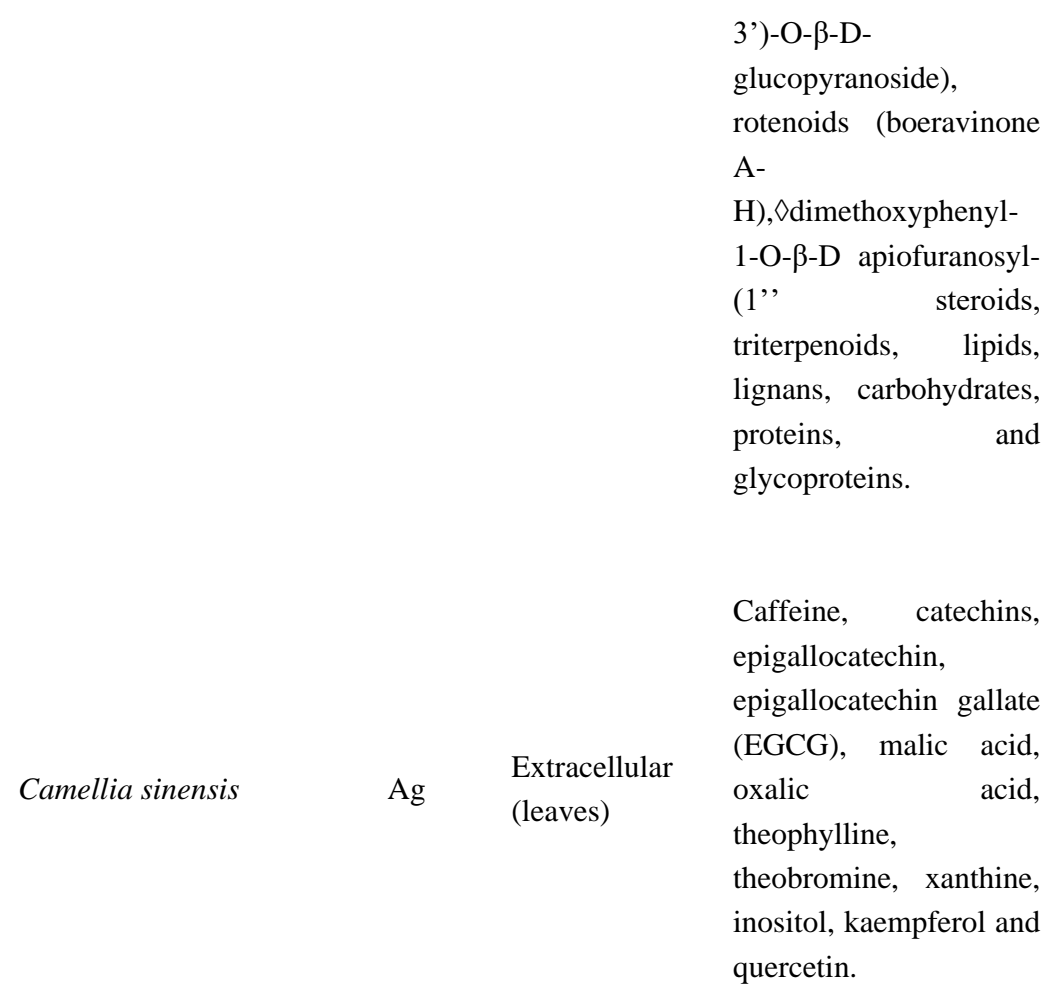

Tribulus terrestris

$\mathrm{Ag}$

Extracellular (fruit)

Extracellular (Inflorescenc)

\section{Continued}

Its compounds may reduce the enlargement of the heart, improve blood pressure dysfunction, and restore antioxidant enzyme activity. Camellia sinensis leaf extract may improve heart health by lowering blood pressure, cholesterol, triglycerides, and preventing plaque buildup in the blood vessels.

Tribulus is used for kidney problems, including kidney stones, painful urination, a kidney disorder called Bright's disease, and as a "water pill" (diuretic) to increase urination; for skin disorders, including eczema (atopic dermatitis), psoriasis, and scabies; for male sexual problems, including erectile dysfunction.

The roots are considered antipyretic and diuretic. Milk of young coconut is diuretic, laxative, antidiarrhoeic and counteracts the effects of poison. The oil is used to treat diseased skin and teeth and mixed with other medicines to make embrocations. 
Abutilon indicum

Pistacia atlantica

Ziziphora tenuior

Ficus carica
Ag

Extracellular (leaves)

Ag

Ag

Leaves
Alkaloid, Saponins, Amino acid, Flavonoids, Glycosides and steroids.

Fatty acids, sterols, triacylglycerols (TAG), tocopherols,

polyphenols, and pigments.

Pulegone (71.2 to $85.3 \%)$, limonene $(0.51$ to $7.8 \%$ ), thymol (1.0 to $4.3 \%)$, and menthone (3.0 to $3.7 \%$ ).

Aldehydes: methylbutanal, 2methylbutanal, (E)-2pentanal, hexanal, and (E)-2-hexanal, alcohols: 1-penten-3-ol, 3-methyl1-butanol, 2methylbutanol, heptanol, benzyl alcohol, (E)-2-nonen-1ol, and phenylethyl alcohol, ketone: 3pentanone, esters: methyl butanoate, methyl hexanoate, hexyl acetate, ethyl benzoate, and methyl salicylate, monoterpenes: limonene and menthol, sesquiterpenes:cubenene, -guaiene, ylangene, copaene, bourbonene, -elemene, -
Indicum is used as an aphrodisiac, demulcent, diuretic, laxative, pulmonary and sedative (leaves). The bark is astringent and diuretic; laxative, expectorant and demulcent (seeds); laxative and tonic, antiinflammatory and anthelmintic (plant); analgesic (fixed oil); diuretic and for leprosy (roots).

gastrointestinal disorders, but there are several pharmacological activities discussed in traditional medicine such as aphrodisiac activities, diuretic, emmenagogue. antimicrobial, antiseptic, expectorant and wound healing preparations. It is used for the treatment of cough, stomach ache, dysentery, fever, uterus infection, gut inflammation and painful menstruation.

gastrointestinal (colic, indigestion, loss of appetite, and diarrhea), respiratory (sore throats, coughs, and bronchial problems), and cardiovascular disorders and as anti-inflammatory and antispasmodic remedy.
Continued 


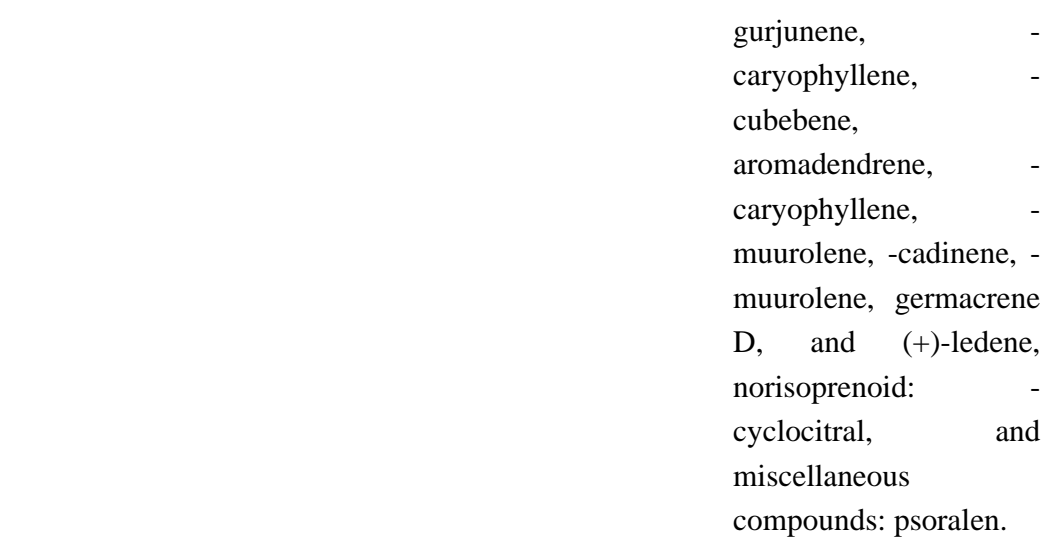

Cymbopogan citratus

Ag Leaves

Acalypha indica

Premma herbacea

Ag

Ag Leaves

Calopropis procera
Geranial (27.04\%), neral (19.93\%) and myrcene (27.04\%).

Cyanogenic glycoside called acalyphin (a 3cyanopyridone derivative) as well as flavonoids, such as kaempferolglycosides mauritianin, clitorin, nicotiflorin, and biorobin. Tannins, $\beta$ sitosterol,

acalyphamide,

aurantiamide, succinimide, and flindersin (a pyranoquinolinone alkaloid).

$4 \beta$-hydroxyasarinin-1-

O- $\beta$ glucopyranoside) along with four iridoid glycosides (10-O-transp-Coumaroylcatalpol,

$4 "-$ hydroxy-

Premnosidic acid and 10coumaroyl-6-O- $\alpha$ rhamnopyranosyl.

Calotropis gigantea Linn., methyl $\beta$ carboline-1-carboxylate

(1),

(+)-

dehydrovomifoliol (2), pleurone (3),
Eglobularinin, O-trans-p-

\section{Continued}

antispasmodic,

hypotensive,

anticonvulsant, analgesic, antiemetic, antitussive, antirheumatic, antiseptic and treatment for nervous and gastrointestinal disorders and fevers.

ganglions, diarrhoea, leprosy, laxative, diuretic gonorrhoea, rheumatism ulcers, ring worms, eczema, intestinal worms, boils and swellings, postpartum pains, scabies, and venereal diseases.

The roots are considered medicinal.

Juice of leaves is rubbed on the body also and applied to the head in fever to reduce temperature. Ripe fruit is eaten. The juice from roots and rhizomes is used in India to treat dropsy, cough, asthma, fever, rheumatism and cholera.

calotropis is used for digestive disorders including diarrhea, constipation and stomach ulcers; for painful conditions including 


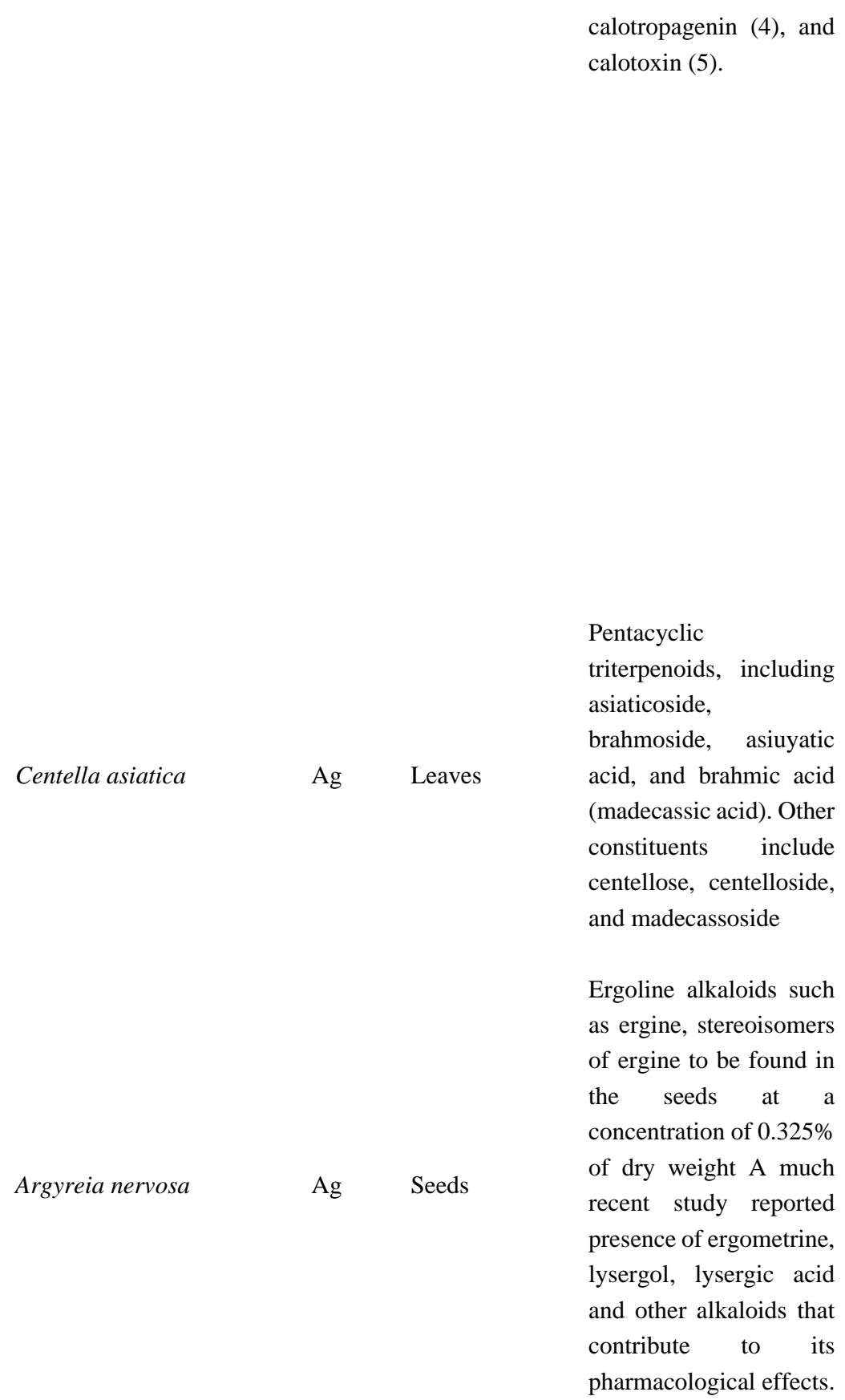

Psoralea carylifolia

Ag Seeds

Coumarins, flavonoids, and meroterpenes.

-O-fatty acid esters (1), $\beta$-sitosterol (2), Brassica rapa

Ag Leaves chlorophyll a (3) and phytyl fatty acid esters' $\beta$-sitosteryl-3 $\beta$ -

\section{Continued}

toothache, cramps, and joint pain; and for parasitic infections including elephantiasis and worms.

Some people use calotropis for syphilis, boils, inflammation (swelling), epilepsy, hysteria, fever, muscular spasm, warts, leprosy, gout, snakebites, and cancer. In inhalation therapy, smoke from the bark is inhaled for coughs, asthma, and to cause sweating.

the herb is recommended for the treatment of various skin conditions such as leprosy, lupus, varicose ulcers, eczema, psoriasis, diarrhoea, fever, amenorrhea, diseases of the female genitourinary tract and also for relieving anxiety and improving cognition.

used extensively as an adaptogen in the Ayurvedic system of medicine.

Pharmacological activities such as anti-oxidant, antiinflammatory, antirheumatic, immunomodulatory, adaptogenic and hepatoprotective.

It is good to cure dyspnoea, asthma, bronchitis and various disorders associated with respiratory tract. It is used to relieve indigestion and also used to cure worm infestation. Seeds of this plant are used to cure various skin disorders.

A decoction of the leaves or stems is used in the 16.4 treatment of cancer. The powdered seed is said to be a folk remedy for 


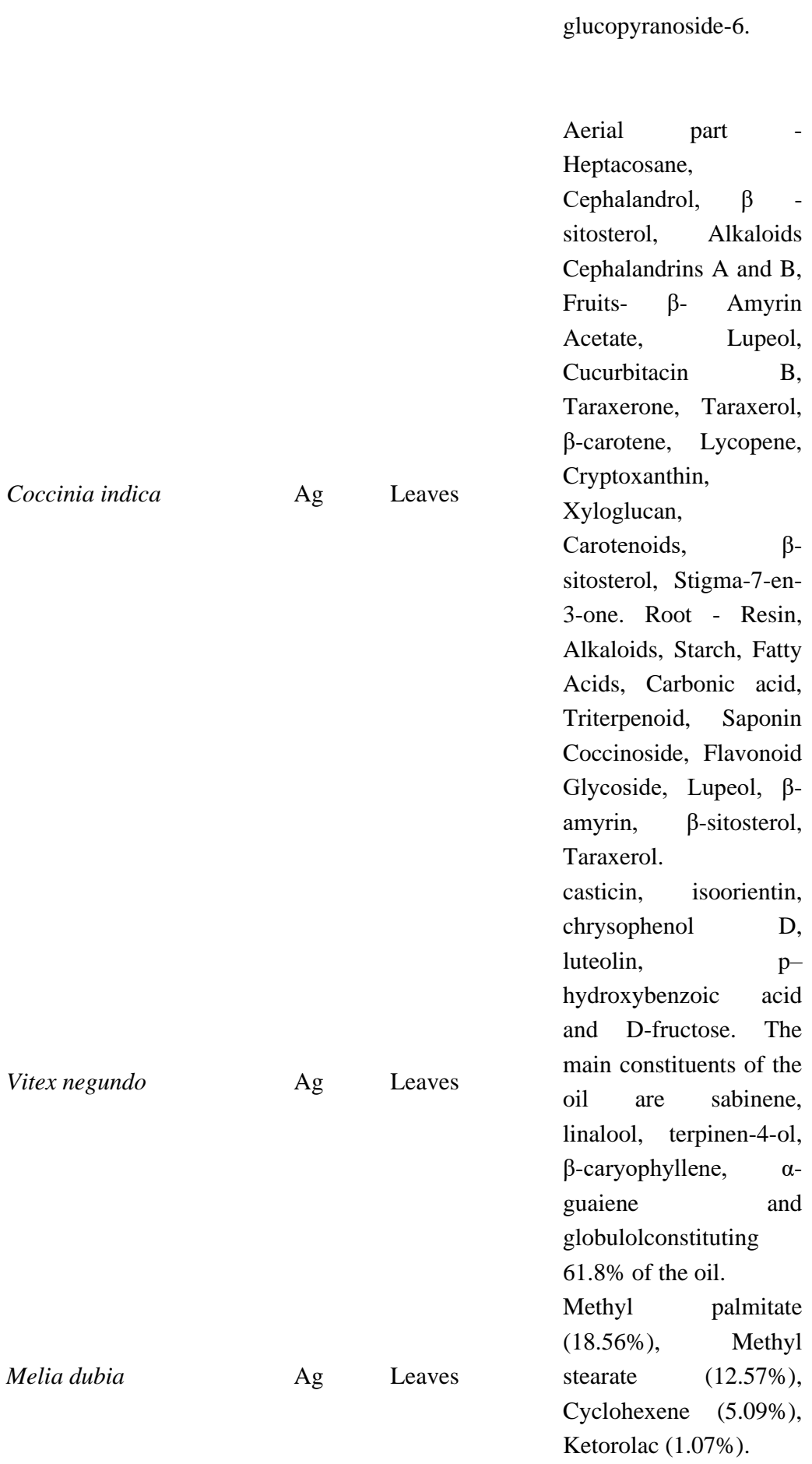

-

sitosterol, Stigma-7-en-

3-one. Root - Resin,

Alkaloids, Starch, Fatty

Acids, Carbonic acid,

Triterpenoid, Saponin

Coccinoside, Flavonoid

Glycoside, Lupeol, $\beta$ -

amyrin, $\quad \beta$-sitosterol,

Taraxerol.

casticin, isoorientin,

chrysophenol D,

luteolin, $\quad \mathrm{p}$ -

hydroxybenzoic acid

and D-fructose. The

main constituents of the

oil are sabinene,

linalool, terpinen-4-ol,

$\beta$-caryophyllene, $\quad \alpha$ -

guaiene

and

globulolconstituting

$61.8 \%$ of the oil.

Methyl palmitate

(18.56\%), Methyl

stearate (12.57\%),

Ketorolac (1.07\%).

Flavonoids, alkaloids, fatty acids, terpenoids, polysaccharides,

vitamins, sterols, proteins, and minerals.
$10-20$

Continued

cancer. The crushed ripe seeds are used as a poultice on burns.

It is extensively used in traditional medicine for the treatment of leprosy, jaundice, asthma, bronchitis, skin eruptions, burns, tongue sores, earache, indigestion, eye infections, nausea, insect bites, and fever.

10-30

potent anti-inflammatory activity. These constituents contribute various pharmacological activities as antiinflammatory, antioxidant,

antinociceptive, antiulcer, free radicals scavenging,

hepatoprotective and many more.

Effective for treating colic, leprocy, itching, scabies.

Its use as a purgative, cardiac tonic, emollient, muscle relaxant, and antiinflammatory and diuretic treatment makes it important in herbal medicine. Purslane has also been used in the treatment of osteoporosis and psoriasis. Portulaca oleracea is of considerable importance
Portulaca oleracea Ag Leaves 
Thevetia peruviana

Pogostemon

benghalensis

Ag Leaves

Trachyspermum amni

Ag Latex carbohydrates,

terpenoids, steroids.

Monoterpenes,

sesquiterpenes and their oxygenated derivatives such as alcohols, aldehyde, ketones, acids and esters.

\section{Continued}

to the food industry and also possesses a wide spectrum

pharmacological

properties such as neuroprotective,

antimicrobial,

antidiabetic, antioxidant, anti-inflammatory,

antiulcerogenic, and anticancer activities, which are associated with its diverse chemical constituents, including flavonoids, alkaloids, polysaccharides, fatty acids, terpenoids, sterols, proteins, vitamins, and minerals.

Thevetia peruviana is used medicinally throughout the tropics in spite of its toxicity. A bark or leaf decoction is taken to loosen the bowels, as an emetic, and is said to be an effective cure for intermittent fevers. In Senegal water in which leaves and bark were macerated is taken to cure amenorrhoea.

it is used in herbal medicine as an aphrodisiac,

antidepressant and antiseptic. The ethnobotany of the plant reveals that the plant leaves are also useful in the treatment of kidney stone. The oil is used in aromatherapy to treat skin complaints.

The fruit possesses stimulant, antispasmodic and carminative properties and is used traditionally as 87 an important remedial agent for flatulence, atonic dyspepsia, diarrhea, abdominal tumors, abdominal pains, piles, 


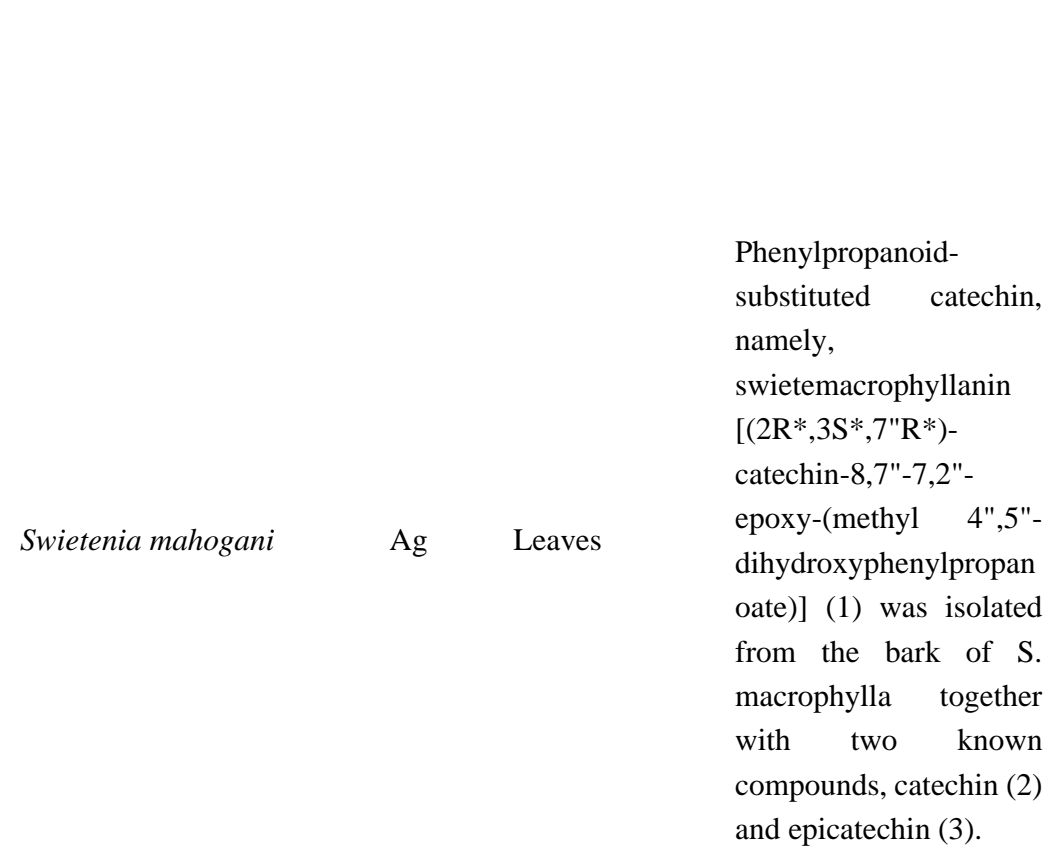

Musa paradisiacal

Ag

Peel

Moringa olefera

Ag Leaves
Phenylpropanoid-

substituted catechin,
namely,
swietemacrophyllanin
[(2R*,3S*,7"R*)-
catechin-8,7"-7,2"-
epoxy-(methyl 4",5"-
dihydroxyphenylpropan
oate)] (1) was isolated
from the bark of $\mathrm{S}$.
macrophylla together
with two known
compounds, catechin (2)
and epicatechin (3).

Sugars, lipids proteins and some minerals

9-octadecenoic acid (20.89\%), L-(+)ascorbic acid- 2,6dihexadecanoate

(19.66\%), 14-methyl-8hexadecenal $(8.11 \%)$, 4hydroxyl-4-methyl-2-

pentanone $(7.01 \%), 3-$ ethyl-2, $4-$ dimethylpentane

(6.14\%), phytol (4.24\%),

octadecamethyl-

cyclononasiloxane

(1.23\%), 1, 2-benzene dicarboxylic acid $(2.46 \%), \quad 3, \quad 4-$ epoxyethanone Comprising (1.78\%), N(-1-methylethyllidene)benzene ethanamine $(1.54 \%), 4,8,12,16-$ tetramethylheptadecan- and bronchial problems, lack of appetite, galactogogue, asthma and amenorrhoea.

antimicrobial, antiinflammatory,

hepatoprotective, antidiarrheal, antiulcer, depressant, anticonvulsant and neuropharmacological, anti-diabetic, anti-HIV, immunomodulator, insect repellent and larvicidal, antifungal, antioxidant, analgesic, platelet aggregation inhibitors, antimutagenic and anticancer.

The flower of this plant is used to treat ulcers, dysentery, and bronchitis and cooked flowers are good food for diabetics. The astringent ashes of the unripe banana peel and leaves are used in the treatment of dysentery and diarrhea and also for the treatment of malignant ulcers.

Various parts of this plant such as the leaves, roots, seed, bark, fruit, flowers and immature pods act as cardiac and circulatory stimulants, possess antitumor, antipyretic, antiepileptic, antiulcer, antispasmodic, diuretic, antihypertensive, cholesterol lowering, antioxidant, antidiabetic 
Continued

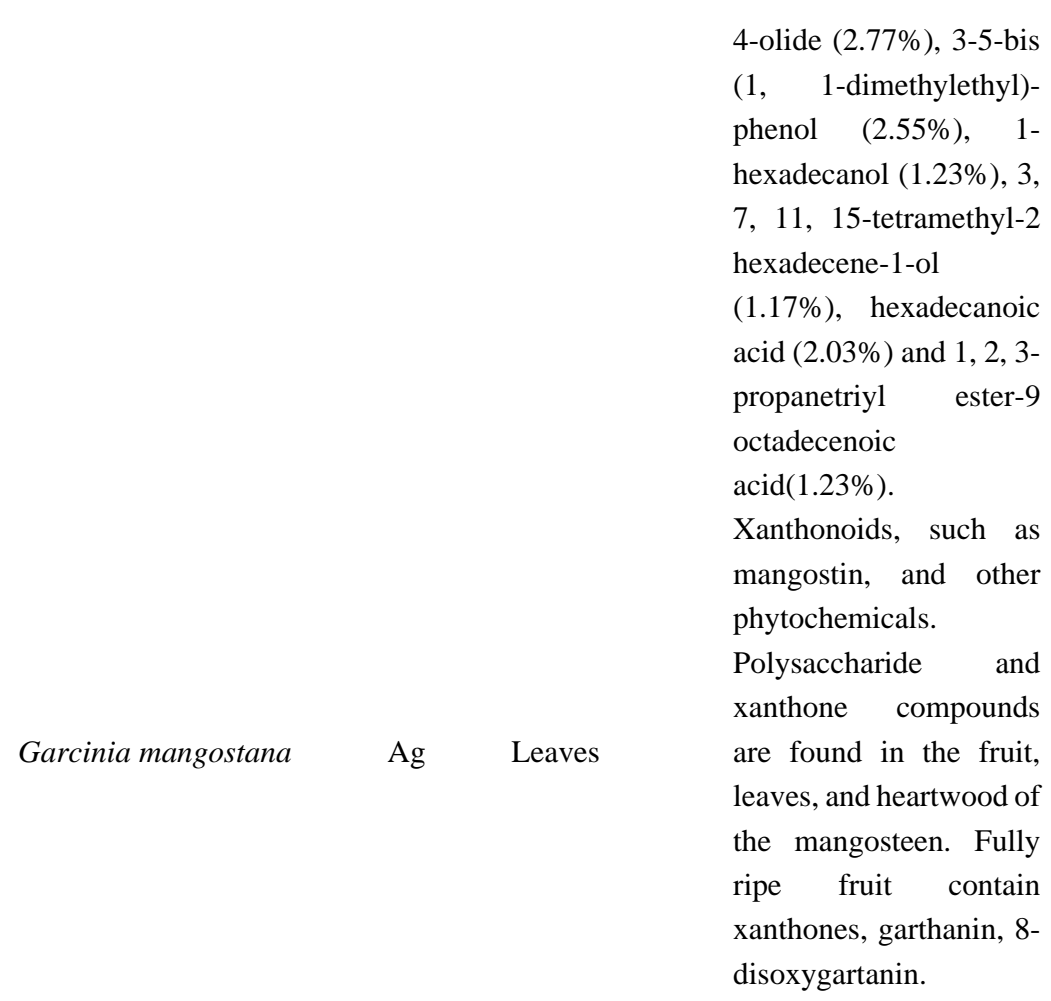

1, 1-dimethylethyl)phenol (2.55\%), 1hexadecanol (1.23\%), 3, , 15-tetramethyl-2

$(1.17 \%)$, hexadecanoic acid $(2.03 \%)$ and 1, 2, 3-

ctadecenoic $\operatorname{acid}(1.23 \%)$

Xanthonoids, such as mangostin, and other terthienylmethanol, tochemicals.

Polysaccharide and are found in the fruit, leaves, and heartwood of the mangosteen. Fully disoxygartanin.

Coumestans, alkaloids, flavonoids, glycosides, polyacetylenes,

triterpenoids. The leaves contain stigmasterol, $\beta$ -

the pericarp (peel, rind, hull or ripe) of GML as a traditional medicine for the treatment of abdominal pain, diarrhea, dysentery, infected wound, suppuration, and chronic ulcer.

- $\quad$ The whole plant is used as antiseptic

febrifuge, tonic, deobstruent in hepatic and spleen enlargement and is emetic.

- In combination with aromatics, the juice is given in anemia, catarrh and cough.

- The plant is also used as scalp tonic for promoting hair growth.

edelolactone and demethylwedelolactone -7-glucoside. 


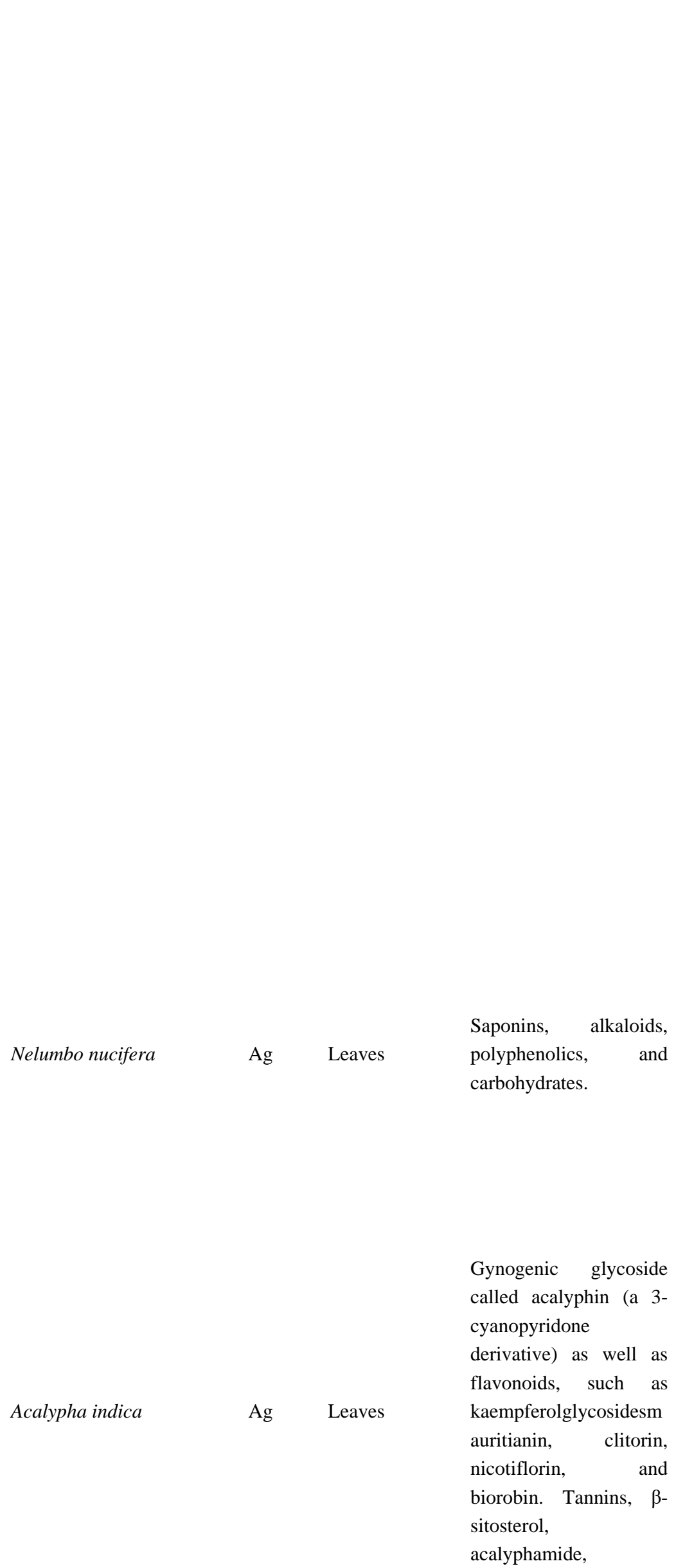

enlargement.

- The fresh juice of the leaves is given in the treatment of edema, fevers, liver disorders, and rheumatic joint pains; it is also used to improve the appetite and to stimulate digestion.

- The juice is given with honey to treat upper respiratory congestion in children.

- The hair oil is prepared from boiling the fresh leaves with either coconut or sesame oil renders the hair black and lustrous.

Traditionally rhizomes, leaves, and seeds have been used as folk medicines, Ayurveda, Chinese traditional medicine, and oriental medicine. While leaves are used for hematemesis, epistaxis, and hematuria, the flowers are used for lowering blood sugar levels, diarrhea, cholera, fever, and hyperdipsia.

The leaf of Acalypha indica is used across many communities to treat and manage a number of diseases including ganglions, diarrhoea, leprosy, laxative, diuretic gonorrhoea, rheumatism ulcers, ring worms, eczema, intestinal worms, boils and swellings, post-

\section{Continued}




$\begin{array}{ll} & \begin{array}{l}\text { aurantiamide, } \\ \text { succinimide, and } \\ \text { flindersin } \\ \text { pyranoquinolinone } \\ \text { alkaloid) have also been } \\ \text { isolated. }\end{array} \\ & \\ \text { Allium sativum Ag Leaves } & \\ & \\ & \text { Alliin, ajoene, diallyl } \\ \text { sulfide (DAS), diallyl } \\ \text { disulfide (DADS) and } \\ \text { diallyl trisulfide } \\ \text { (DATS). }\end{array}$

Aloe vera

Ag Leaves

Citrus sinensis

Ag Peel
Proteins, lipids, amino acids, vitamins, enzymes, inorganic compounds and small organic compounds.

Flavonoids.

steroids,

hydroxyamides, alkanes and fatty acids, coumarins, peptides, carbohydrates,

$10-35$ carbamates and alkylamines, carotenoids, volatile compounds

\section{Continued}

partum pains, scabies, and venereal diseases.

Garlic is reported to be a wonderful medicinal plant owing to its preventive characteristics in cardiovascular diseases, regulating blood pressure, 4-22 lowering blood sugar and cholesterol levels, effective against bacterial, viral, fungal and parasitic infections, enhancing the immune system and having antitumoral.

Application of aloe to skin may increase the absorption of steroid creams such as hydrocortisone. It reduces the effectiveness and may increases the adverse effects of digoxin and digitoxin, due to its potassium lowering effect. Combined use of Aloe vera and furosemide may increase the risk of potassium depletion. It decreases the blood sugar levels and thus may interact with oral hypoglycemic drugs and insulin.

C. sinensis is consumed all over the world as an excellent source of vitamin $\mathrm{C}$, which is a powerful natural antioxidant that builds the body's immune system. It has been used traditionally to treat ailments like 
Eucalyptus hybrid

Memecylon edule

Nebumbo nucifera
Ag Peel

Ag Leaves

Ag Leaves
Terpenes, including 1,8cineole

$50-150$

Monoterpene compound

1,5, heptadien-4-one, 3,3,6-trimethyl, 1 monolinoleoylglycerol trimethylsilyl ether, 9, 12-octadecanoic acid (Z,Z)-, $1,2-$ benzenedicarboxylic acid, diisooctyl ester and 1,5,heptadien-4-one, 3,3,6-trimethyl were present only in petroleum ether extract.

1-decane,

1 -

hexadecanol,

$1-$ tridecanol,

$2-$ pentadecanone, 6,10,14trimethyl-, 4,18,12,16tetramethylheptadecan-

4-olide, 9, 12octadecenoic acid, methyl ester, (E,E)-, 9nonadecene, 9octadecenoic acid (Z)-, methyl ester, dascarpidan-1-

methanol, acetate (ester), eicosanoic acid, heptacosane,

heptadecanoic acid, hydroxylamine, odecyl-, nonadecane, octacosane,

pentacosane,

phenol,2,4,bis(1,1-

dimethylethyl)-, phytol, tetradecane,

tetradecane, 2,6,10-

trimethyl-, tetradecanoic acid and tridecane.

Flavonol miquelianin, as well as the alkaloids (+)$(1 R)$-coclaurine and $(-)$ (1S)-norcoclaurine, can be found in the leaves of $N$. nucifera. The plant
The plant has been reported to possess potent antiseptic, astringent, deodorant, diaphoretic, expectorant, inhalant, insect repellant, rubefacient and suppurative properties.

Continued

Anjani - Memecylon edule is an Ayurvedic herb used in the treatment of skin diseases, menstrual disorders, burning sensation of the body, burning urination, bruises and conjunctivitis.
While leaves are used for hematemesis, epistaxis, and hematuria, the flowers are used for lowering blood sugar levels, diarrhea, cholera, fever, 
Datura metal

Carica papaya

Vitis vinifera
Ag Leaves

Ag

Leaves

Ag Fruits also contains nuciferine and aporphine.

Phytochemicals, including carotenoids and polyphenols, benzyl isothiocyanates and benzyl glucosinates.

Anthocyanins,

hydroxycinnamic acids, proanthocyanidins, Stilbenoids. and hyperdipsia.

Rhizomes are promoted have purported diuretic, antidiabetic, and antiinflammatory properties

The seeds of Datura are analgesic, anthelmintic and anti-inflammatory and as such, they are used in the treatment of stomach and intestinal pain that results from worm infestation, toothache, and fever from inflammation. The juice of its fruit is applied to the scalp, to treat dandruff and falling hair.

Papaya lowers high cholesterol levels as it is a good source of fiber. Papaya effectively treats and improves all types of digestive and abdominal disorders. It is a medicine for dyspepsia, hyperacidity, dysentery and constipation. Papaya helps in the digestion of proteins as it is a rich source of proteolytic enzymes. Even papain-a digestive enzyme found in papaya is extracted, dried as a powder and used as an aid in digestion. Ripe fruit consumed regularly helps in habitual constipation. It is also reported that papaya prevents premature aging. It may be that it works because a poor digestion does not provide enough nutrients to our body. The fruit is regarded as a remedy for abdominal disorders.

Unripe grapes were used for treating sore throats, and raisins were given as treatments for (tuberculosis), constipation and thirst.

\section{Continued}

160 
Cinnamomum camphora

Coleus amboinicus

Coleus aromaticus

Curcuma longa
$\mathrm{Ag} / \mathrm{Au} \quad$ Extracellular

Ag

Extracellular

Ag

Extracellular

Ag
D-camphor, linalool, 1,8-cineole, safrole, and $\alpha$-terpineol.
$55-80$

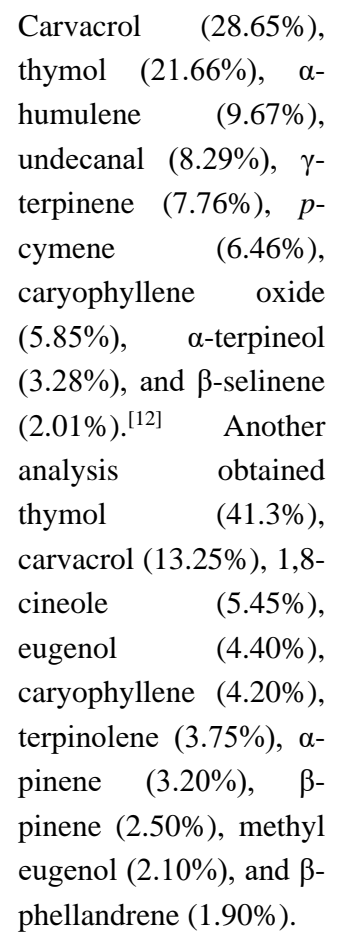

Thymol (57.7-66.4\%), $\gamma$-terpinene $(5.811 .7 \%)$, p-cymene (4.1-14.2\%), (E)-caryophyllene (2.6$3.6 \%)$, caryophyllene oxide (1.3-1.5\%), and 1octen-3-ol (1.0-1.8\%).

60-70\% Carbohydrates, 6-13\% water, 6-8\% protein, 5-10\% fat, 3$7 \%$ dietary minerals, $3-$ $7 \%$ essential oils, $2-7 \%$ dietary fiber, and $1-6 \%$ curcuminoids.
Ripe grapes were used for the treatment of cancer, cholera, smallpox, nausea, skin and eye infections as well as kidney and liver diseases.

Camphor (Cinnamomum camphora) is a terpene (organic compound) that's commonly used in creams, ointments, and lotions. Camphor oil is the oil extracted from the wood of camphor trees and processed by steam distillation. It can be used topically to relieve pain, irritation, and itching.

It is a folkloric medicinal plant used to treat malarial fever, hepatopathy, renal and vesical calculi, cough, chronic asthma, hiccough, bronchitis, helminthiasis, colic, convulsions, and epilepsy.

It is a folkloric medicinal plant used to treat malarial fever, hepatopathy, renal and vesical calculi, cough, chronic asthma, hiccough, bronchitis, helminthiasis, colic, convulsions, and epilepsy.

The medicinal use of this plant is part of traditional Chinese medicine and traditional medicine of India (Ayurveda), used to treat different conditions of inflammatory origin
Continued 


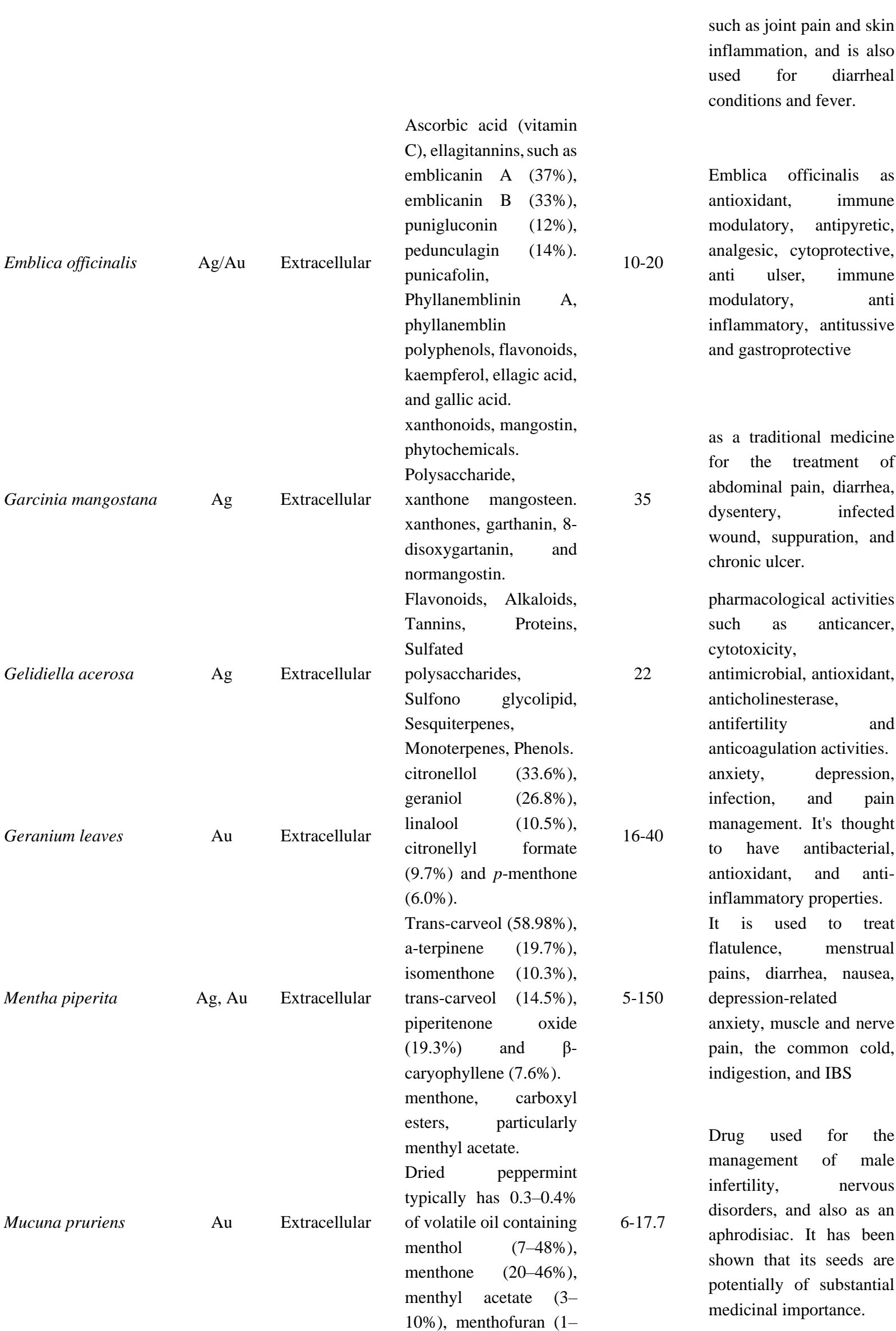




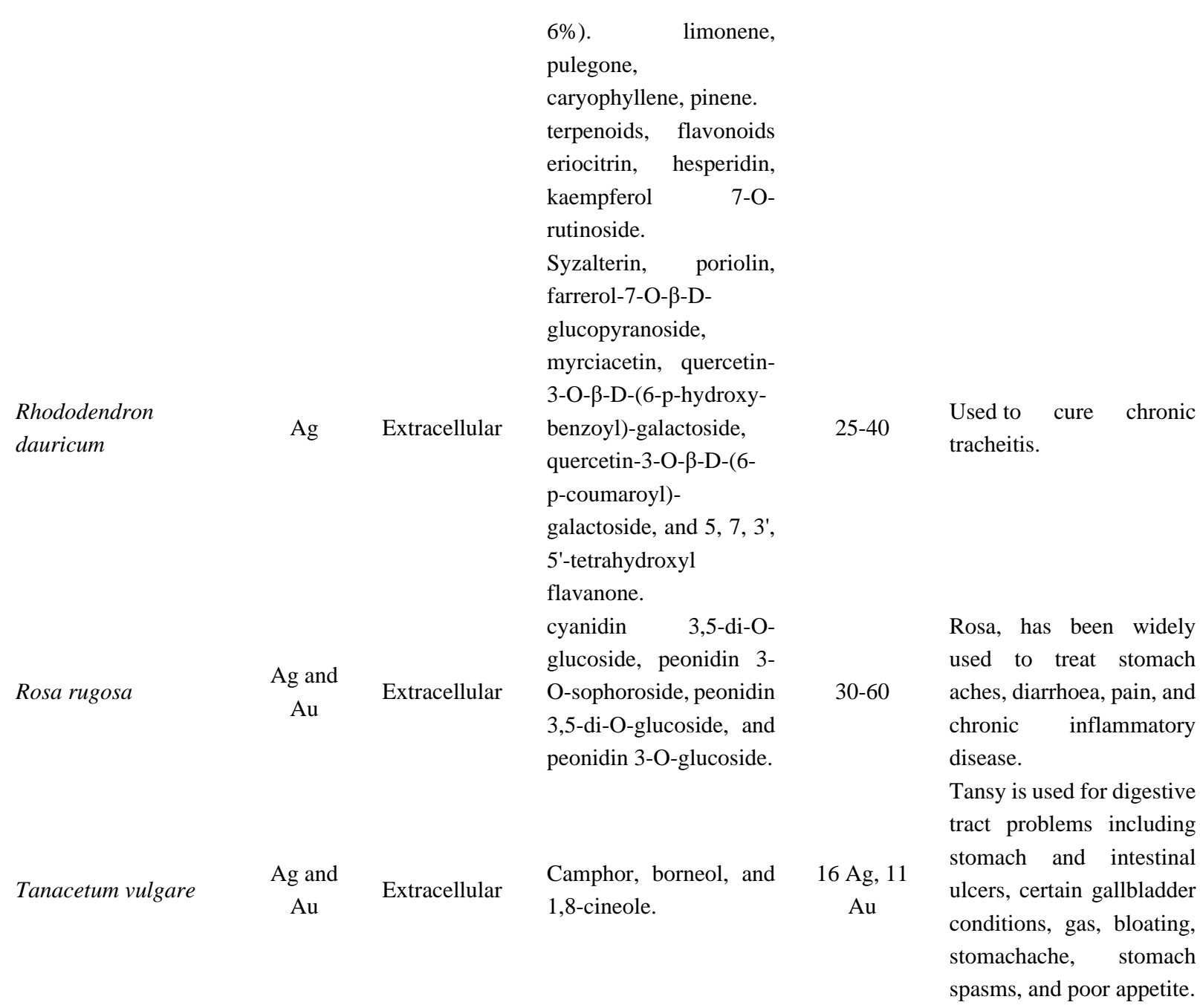

Continued

(D) Fungi

Phoma sp.3.2883

Fusarium oxysporium

Verticillium

Aspergillus fumigatus

Trichoderma

asperellum

Phaenerochaete

chysosporium

Fusarium oxysporum

T. viride

F. oxysporangium

Phaenerochaete

crysosporium

F. solani USM 3799

F. semitectum

F. acuminatum

A.Fumigatus

Coriolus versicolor

A.Nigre

P. glomerata

Penicillinum

brevicompactum
Ag

Extracellular

Extracellular

Intracellular

Ag

Ag

Ag

Extracellular

Extracellular

Ag

Magnetite

Ag

Ag

Ag

Ag

Ag

Ag

Ag

Ag

Ag

Ag

Ag

Extracellular

71.06-74.46 


\begin{tabular}{|c|c|c|c|c|}
\hline Cladosporium & $\mathrm{Ag}$ & Spherical & $10-100$ & \\
\hline clodasporiodes & & & & 187 \\
\hline $\begin{array}{l}\text { Penicillinum } \\
\text { fellutanum }\end{array}$ & $\mathrm{Ag}$ & Spherical & $5-25$ & 187 \\
\hline F. oxysporum & $\mathrm{Ag}$ & & 8-14 & 187 \\
\hline Valvuriella volvacea & $\mathrm{Ag}$ & Spherical & $20-150$ & 187 \\
\hline F. oxysporum & $\mathrm{Si}$ & $\begin{array}{l}\text { Quasi- } \\
\text { spherical }\end{array}$ & $5-15$ & 187 \\
\hline F. oxysporum & $\mathrm{Ti}$ & Spherical & $6-13$ & 187 \\
\hline F. oxysporum & $\mathrm{Zr}$ & $\begin{array}{l}\text { Quasi- } \\
\text { spherical }\end{array}$ & 3-11 & 187 \\
\hline F.oxysporum & $\mathrm{Pt}$ & Trigonal & $10-50$ & 187 \\
\hline F. oxysporum & Magnetite & $\begin{array}{l}\text { Quasi- } \\
\text { spherical }\end{array}$ & $20-50$ & 187 \\
\hline Verticillum $s p$ & Magnetite & $\begin{array}{l}\text { Cubo- } \\
\text { octahedral }\end{array}$ & $100-400$ & 187 \\
\hline F. oxysporum & $\mathrm{CdSe}$ & Spherical & $9-15$ & 187 \\
\hline F. oxysporum & $\mathrm{SrCO}_{3}$ & Needle shaped & & 187 \\
\hline F. oxysporum & $\mathrm{BaTiO}_{3}$ & $\begin{array}{l}\text { Quasi- } \\
\text { spherical }\end{array}$ & 4 & 187 \\
\hline F. oxysporum & $\mathrm{Bi}_{2} \mathrm{O}_{3}$ & $\begin{array}{l}\text { Quasi- } \\
\text { spherical }\end{array}$ & $5-8$ & 187 \\
\hline \multicolumn{5}{|l|}{ (E) Yeast } \\
\hline Candida glabrate & $\mathrm{CdS}$ & Intracellular & 200 & 188 \\
\hline MKY3 & $\mathrm{Ag}$ & Extracellular & $2-5$ & 188 \\
\hline
\end{tabular}

\subsection{Green synthesis of metallic nanoparticles}

It is well known that few medicinal plants exhibit antioxidant properties. Thus they can act as a biological source of reducing agents. On this belief choice of plants for this purpose was those carrying medicinal and aromatic properties. Solution temperature, the concentration of metal salt and reducing agent, and reaction time all influence the shape and size of the particle. Shiv Shankar et al. have reported synthesising silver and gold nanoparticles using a decoction solution of Azadirachta indica. However, the nanoparticles synthesised by them are in the range of $50-100 \mathrm{~nm}$ and are not well separated from each other and tend to form structures wherein large particles are capped in small particles. ${ }^{[40-41]}$ Jose and coworkers have shown that live alfalfa plants, when supplied with $\mathrm{Au}^{3+}$ ions, reduce them to $\mathrm{Au}^{0}$ state and absorb them, resulting in the internal formation of gold nanoparticles. JoseYacaman's group has also extended this to demonstrate the synthesis of silver nanoparticles within alfalfa sprouts by supplying the plants with $\mathrm{Ag}^{+}$ions. ${ }^{[42-43]}$ Mallikarjuna et al. have synthesised silver nanoparticles using the leaf broth of Ocimum sanctum to reduce and stabilising agents. While these reports demonstrated the possibility of synthesising metal nanoparticles using plants, they suffer from the inherent complication of being intracellular, making the isolation of particles an additional difficult job. The internal accumulation of metal in plants can occur both via complexation of the metal ion with a suitable bio-ligand in its native oxidation state or after its reduction to a lower oxidation state. ${ }^{[44]}$

Extract from well-known commercial plants like Coffea Arabica and Cymbopogon citratus was used as green reagents in AgNPs synthesis. Thus, by reducing silver nitrate in a tea extract or epicatechin solution of varying concentrations, spherical silver nanoparticles were formed with controllable size distribution depending upon the concentration of tea extract and epicatechin in the samples. Jayaseelam and coworkers have synthesised AuNPs using Abelmoschus esculents, monodispersed and crystalline with uniform shape, and showed the potential antifungal activity. ${ }^{[45]}$ Similarly, Satishkumar et al. have synthesised nanoparticles of silver using Morinda citrifoloa. Synthesis of AgNPs by reduction of aq. Ag ions using Annona squamosal have resulted in polydisperse stable spherical nanoparticles. ${ }^{[46-47]}$ Among the various biological methods used for nanoparticle synthesis, plant-based materials seem to be the best candidates, and they are suitable for large-scale biosynthesis of nanoparticles. Plant sources such as plant leaf, roots, latex, seed, and stem are used 
for metal nanoparticle synthesis and are shown in Fig. 3. Fig. 4. Plants have been known to bio-mineralise calcium carbonate, silica, and even magnetite internally. Like microorganisms, plants have also been used to purify heavy metal ions from contaminated soil and water. Certain plants are known to hyper-accumulate these heavy metals or can even be induced to hyper-accumulate within different parts of plants. The significant advantage of using plant extracts for silver nanoparticle synthesis is that they are readily available, safe, and non-toxic in nature. Most cases have a wide variety of metabolites that can reduce silver ions and are quicker than microbes in the synthesis. ${ }^{[48]}$ To circumvent the problem of the internalisation of nanoparticles, plant extracts instead of living plants are used. One of the objectives in using plant extracts was to achieve a rapid synthesis of nanoparticles, unlike the usual biosynthetic process involving microorganisms that usually consume 2 to 4 days to reduce metal ions. ${ }^{[49-50]}$

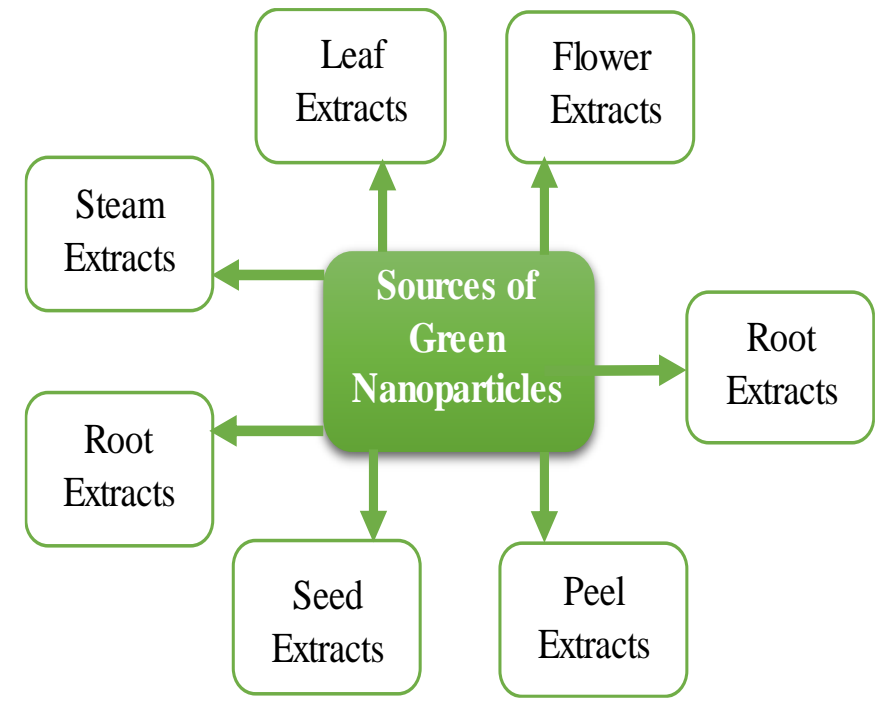

Fig. 3 Various green sources for synthesis of bio-nano particles.

The green chemistry approaches for synthesis of nanomaterials have been extended from the lower class of organisms to higher forms of plants, leading to a green chemistry route because it does not require elaborate processes such as intracellular synthesis and multiple purification steps, and maintenance of microbial cell culture. They also make the nanoparticles biologically more effective. In the green chemistry approach of synthesis, the reaction is usually carried out at room temperature, although a bit of heating below $100^{\circ} \mathrm{C}$ was applied in some processes. The high amount of phenolic compounds in the plant extract are generally supposed to influence the reduction process and stabilise nanoparticles preventing agglomeration. These nanoparticles are studied for their antibacterial and catalytic properties. ${ }^{[51]}$

The possibility of reducing metal ions by plants and the presence of metal completing agents entice a materials scientist to use plants to synthesis nanoparticles, control their size and shape, and experiment to form nanoparticles of low reduction potential metals. Meanwhile, the possibility of silver reduction using oxalic acid solution mechanism was shown in
The possibility of synthesizing nanoparticles of different compositions using plants would offer an environmentally friendly alternative to the existing potentially toxic chemical and physical preparations. This would also help stave off the growing apprehensions related to environmental degradation and biological hazards apart from being a cost-effective process with the potential to scale up for large-scale synthesis. Though considered a modern science, the concept of nanotechnology has its history dating back to the $9^{\text {th }}$ century. The artist of Mesopotamia uses nanoparticles of gold and silver to generate a glittering effect on pots. The first scientific description of the properties of nanoparticles is provided in 1857 by Michael Faraday. The great physicist of $20^{\text {th }}$ century Nobel laureate Professor R. Feynman delivered a first illuminating talk in 1959 on Nanotechnology under the title 'There is plenty of room at the Bottom.' He consciously explored the possibility of direct manipulation of the individual atoms to be an effective and powerful form of synthetic chemistry. Of course, Feynman explained nanotechnology concepts too early, and he was aware that possibly the scientific community would not believe in his concept. ${ }^{[52-53]}$
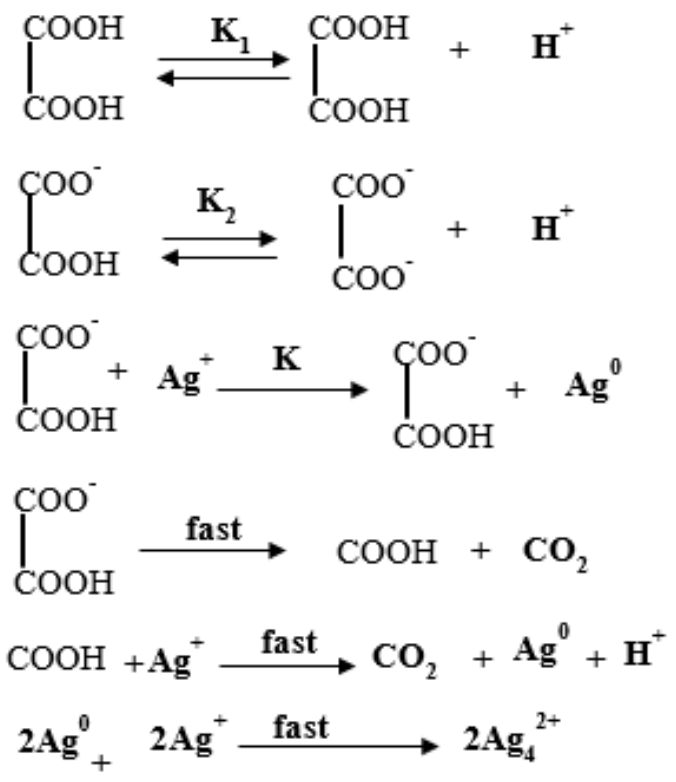

(Yellow color: $\lambda_{\max }=425 \mathrm{~nm}$ )

Fig. 4 Reduction of $\mathrm{Ag}^{+}$ions using an oxalic acid solution.

Nanotechnology is an emerging field of science and is under continuous evolution. There is a broad scope of research in nanotechnology. Nanotechnology remains in search of materials with exotic properties which can be used for the development of humanity. Research in nanotechnology was having so many limitations as nanoparticles are invisible, and the manipulation at the nanoscale was another challenge. However, soon after discovering an electron microscope by Knoll and Ruska, it becomes possible to manipulate and analyse materials at the nanoscale. ${ }^{[54-55]}$ Nanoparticles are a cluster of atoms in a $1-100 \mathrm{~nm}$ size range. Nanoparticles are 
essential building blocks to make new materials with tailored optical, magnetic, mechanical, and electrical properties. They find a wide range of applications such as different types of sensors, catalysts, support, and reducing media. Nanoparticles can have various shapes like a disk, rod, ellipsoids, spherical, flower, ring, etc. The metallic nanoparticles are most promising as they show good antibacterial properties due to their high aspect ratio. The current investigation supports that the usage of silver ions or metallic silver, as well as silver nanoparticles, can be exploited for various applications such as; in medicine for burn treatment, dental materials, coating on stainless steel, textile fabric, sunscreen lotion, water treatment, due to its desirable properties like low toxicity to human cells, high thermal stability and low volatility. ${ }^{[56-57]}$

For many centuries, silver has been employed to treat burns and chronic wounds and make water potable. During developmental stages, silver nitrate was used to treat venereal diseases and fistulae from salivary glands. The medicinal properties of silver are known for about 2000 years. Silver is well known antimicrobial agent against a wide range of over 650 microorganisms. Recently, silver is finding use in the form of silver nanoparticles. In the ancient Indian medicinal system, Ayurveda silver has been described as a therapeutic agent against various diseases. Though other transition metals are also showing antimicrobial properties, silver is less toxic to animal cells. ${ }^{[58-60]}$ Due to their medicinal and antimicrobial properties, silver nanoparticles have been incorporated into more than 200 consumer products, including clothing, medicines, and cosmetics. Before discovering antibiotics in the $20^{\text {th }}$ century, silver nitrate was used to treat fresh burns in varying concentrations. For several ophthalmic diseases, eye drops containing silver nitrate are used. However, after discovering antibiotics, the use of silver for the treatment of bacterial infection was minimized. Even though currently, due to outbreaks of infectious diseases caused by different pathogenic bacteria and the development of antibiotic resistance, researchers and medical professionals are searching for new antibacterial agents. This has led silver nanoparticles towards new heights of attention. The antimicrobial properties of silver depend upon the size and shape of nanoparticles and the nature of the capping agent used. ${ }^{[61-62]}$

\section{Metallic Silver}

Silver is one of the essential elements that make up our planet. It is a rare but naturally occurring element, slightly more complicated than gold, very ductile, and malleable. Metallic silver was found in early $4000 \mathrm{BC}$, and it is believed to be the third metal after gold and copper were used by ancestors. An ancient civilisation like Roman, Greek, and Egyptian used silver to preserve food and water. The use of silver in the $20^{\text {th }}$ century increased for its effectiveness in water purification. In addition, silver metals were used to treat ulcers and heal a wound. Pure silver has the highest electrical and thermal conductivity among all metals and has the lowest contact resistance.

Silver can exist in three oxidation states, i.e., $\mathrm{Ag}^{0} \mathrm{Ag}^{1+}$, and $\mathrm{Ag}^{2+}$ respectively. The first two oxidation states are standard, whereas the last oxidation state is unstable in an aqueous environment. The metallic silver is insoluble in water, whereas the salts of silver are soluble in water. The antimicrobial properties of silver depend upon the amount of silver and the rate of its release as $\mathrm{Ag}^{+}$ions. Silver is a noble metal, and it is ordinarily inert, but in a nano form, it loses inertness. When it comes in contact with moisture in the skin and fluid of the wound, it gets ionised. Silver nanoparticles are of interest because of the unique properties, e.g., size, shape depending on optical and magnetic properties, incorporated into antimicrobial applications, biosensors. The ionised silver causes distortion and the death of bacterial cells. Metallic nanoparticles with unique optical and electrical properties have been widely investigated during the past decades; Ag nanoparticles are the most intensively studied metallic nanoparticles because of their unique properties and applications. The properties of AgNPs greatly depend on the morphology of the particles, including the shapes, sizes, and surrounding medium. Using plant and microbes for nanoparticle synthesis by step by step method and optimisation of silver nanoparticles are shown in Fig. 5. Great efforts have been devoted to the synthesis methods and morphological tailoring of silver nanoparticles. ${ }^{[58,60,61-63]}$

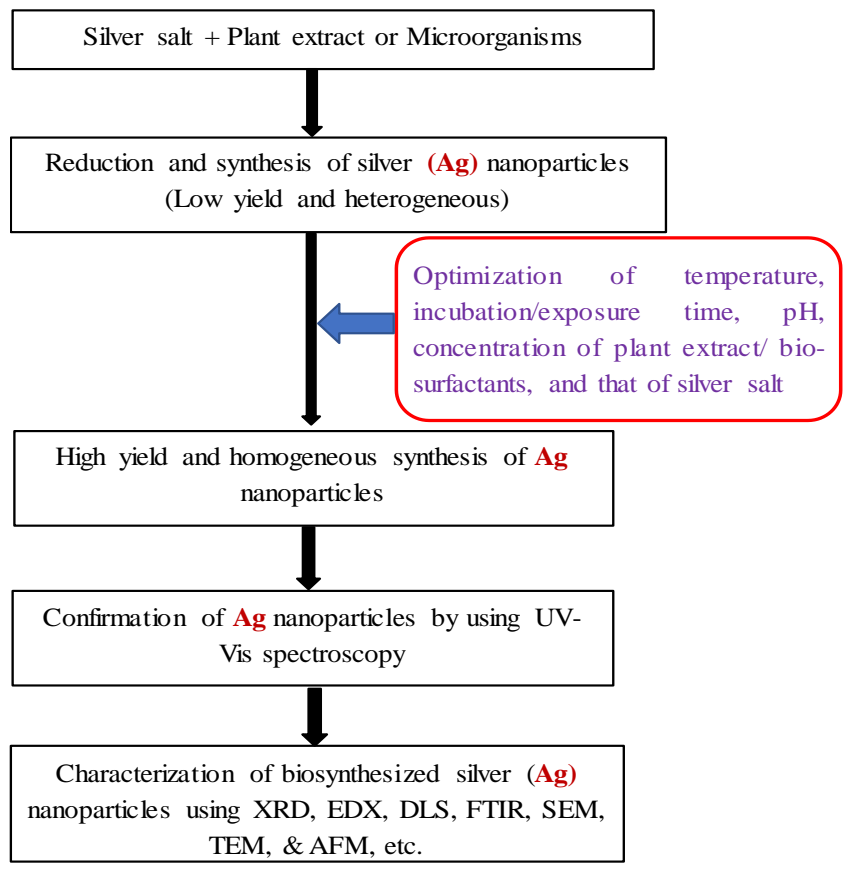

Fig. 5 Step by step biosynthesis method and optimization of silver nanoparticles.

\section{Use of Plant Extract}

\subsection{Green Synthesis of Ag nanoparticles (Green-AgNPs)}

The synthetic route using plant extract can be summarized as per our previously published work: ${ }^{[64]}$ The schematic representation of the synthesis of Green-Ag nanoparticles is shown in Fig. 6. First, the fresh leaves or plant parts are 
collected, cleaned with distilled water, and chopped into small pieces. After that, $50 \mathrm{~mL}$ of double distilled water is added into the beaker and chopped leaves and heated at $600^{\circ} \mathrm{C}$ for $10 \mathrm{~min}$, and then the solution was filtered to prepare leaf extract, which acted as a reducing and capping agent process. Meanwhile, the prepared fresh $\mathrm{AgNO}_{3}(0.01 \%)$ solution was added drop-wise into leaf extract. Next, the mixture was centrifuged at 1000 rpm for separating the AgNPs from the colloidal solution. Finally, the dry AgNPs were obtained and named as GreenAgNPs. While preparing Ag-based leaf extract, the effect of various parameters viz., room temperature, $\mathrm{pH}$ of the reducing agent, reaction temperature, and reaction time are optimised. These are responsible for the size, shape, agglomeration of Green-AgNPs. Furthermore, the $\mathrm{pH}$ alters the charge on biomolecules, temperature increases, the kinetic energy of the molecule, and smaller AgNPs with uniform distributions were formed, which proves controlled parameters are essential for the synthesis of Green-AgNPs.

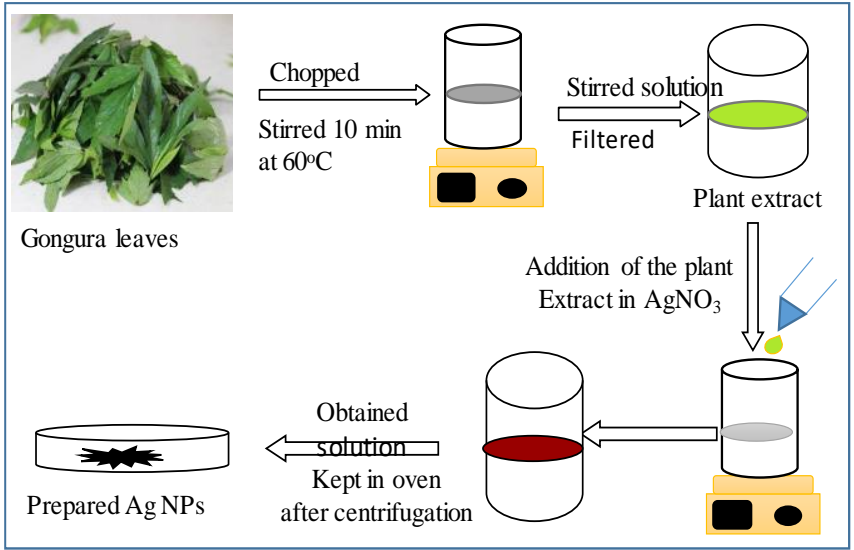

Fig. 6 Schematic representation of the synthesis of Green-Ag nanoparticles.

Bio-nanotechnology has emerged as integrating biotechnology and nanotechnology to develop biosynthetic and environmentally friendly technology to synthesise nanomaterials. The ability of plant extract to reduce metal ions was known since the early 1900s. Plant extracts are ecologically and environmentally friendly materials that are recently widely explored in synthesising silver nanoparticles. The plant containing antioxidants or sugar can be used in the synthesis process, replacing hazardous chemicals like hydrazine, sodium borohydride, etc. The plant extract can work to synthesise nanoparticles so effectively because of reducing and capping agents in them. Numbers of researchers have used various plant extracts to produce nanoparticles. This method does not require the use of any surfactant or capping agents or templates for the synthesis of nanoparticles. Nature has been a source of medicinal plants for more than a thousand years, from the evolution of humanity. ${ }^{\left[{ }^{[6-65]}\right.}$ Over the last two decades, the need for medicinal plants has thrived due to their herbal benefits as natural cosmetics and selfmedication by public and biological effects. Due to increased urbanisation, population explosion, and industrialisation earth's atmospheric condition has deteriorated. Over $80 \%$ world's population uses plant-based medicines for primary health care. The plant produces a wide variety of secondary metabolites, which have multiple functions throughout the plant's life cycle. Plant's secondary metabolites are responsible for various functions such as infertility and germination of pollen grains. Numbers of plant's secondary metabolites are used in food additives, fragrances, pigments, or directly in medicine. Numbers of flavonoids are essential pharmaceuticals. It is believed that polyol components and water-soluble heterocyclic compounds present in leaves were mainly responsible for reducing silver ions and chloroaurate ions. ${ }^{[66]}$ Generally, during the synthesis of nanoparticles, plant extracts are directly used without the isolation of secondary metabolites. However, it is possible to isolate the secondary metabolites by various methods such as Soxhlet extraction, Heat-flux extraction, ultrasonic-assisted extraction, and microwave-assisted extraction. Secondary metabolites obtained from some plants using microwaves are enlisted in Table 2. The relatively high level of steroids, sapogenins, carbohydrates, and flavonoids present in plant extracts reducing agents and phytoconstituents as capping agents, which provides stability to silver nanoparticles. It is believed that proteins with amino groups reduce silver ions and act as control during synthesis. After the interaction, the secondary structure of the protein was found to be altered. Plant and their extracts can be beneficial when it comes to metal nanoparticle synthesis. This is because plant extract contains antioxidants which may act as reducing agents. By altering the concentration of $\mathrm{AgNO}_{3}$ (the most common precursor for the synthesis of AgNPs) and the concentration of plant extract, the size and shape of nanoparticles can be controlled. If nanoparticles are produced outside the cell, biosynthesis will be more beneficial, and the number of nanoparticles produced could be massive. The possible reaction mechanism for the NPS synthesis using plants is due to carbonyl groups in aspartic acid and glutamine residues and the hydroxyl residues of proteins responsible for metallic ion reduction.

The primary mechanism considered for the process is plant-assisted reduction due to phytochemicals. The main phytochemicals involved are terpenoids, flavones, ketones, aldehydes, amides, and carboxylic acids. Flavones, organic acids, and quinones are water-soluble phytochemicals responsible for the immediate reduction of ions. Studies have revealed that xerophytes contain emodin, an anthraquinone that undergoes tautomerisation, leading to the formation of silver nanoparticles. The mesophytes found that they contain three types of benzoquinones: cyperquinones, dietchequinone, and remirin. It was suggested that the phytochemicals were involved directly in reducing ions and forming silver nanoparticles. Though the exact mechanism involved in each plant varies as phytochemicals involved vary, the primary mechanism involved is reducing the ions. A possible reaction mechanism scheme of nanoparticles formation using plant extract can be illustrated as below Fig. 7 . 
Table 2. Some secondary metabolites.

\begin{tabular}{lll}
\hline Plant Species & Secondary Metabolites & Solvent \\
\hline Vitis vinifera & $\begin{array}{l}\text { Polyphenol, flavonoids, } \\
\text { diphenols }\end{array}$ & Methanol \\
Cajanus cajan & Pinostrobin, cajaninstilbene & 80\% Ethanol solution \\
Eriobotrya japonica & Catechin, gentistic acid & Methanol \\
Saururus chinensis & Rutin & Ionic liquid \\
Buddleia officinalis & Phenols and luteolin & $95 \%$ Ethanol solution \\
Ipomoea batatas & Phenols & $53 \%$ Ethanol \\
Fagopyrum esculentum & Phenols & Ethanol \\
Phaseolus vulgaris & Phenols & $50 \%$ Ethanol \\
Citrus unshiu & Hesperidin & $70 \%$ Ethanol solution \\
Arctium lappa & Coffeic acid & Ionic liquid \\
Gymnema sylvestre & Oleanolic acid & $90 \%$ ethanol \\
Glycine max & Isoflavone & Ethanol \\
Silybum marianum & Silymarin & $81.5 \%$ Ethanol \\
Chaenomeles sinensis & Oleanolic and urosolic acid & \\
Laurus nobilis & Essential oils & Water \\
Elletaria cardamomum & Essential oils & Solvent Free \\
Nelumbo nucifera & N- nornuciferine, O0nornuciferine & Ionic liquid \\
& and nuciferine & \\
\hline
\end{tabular}

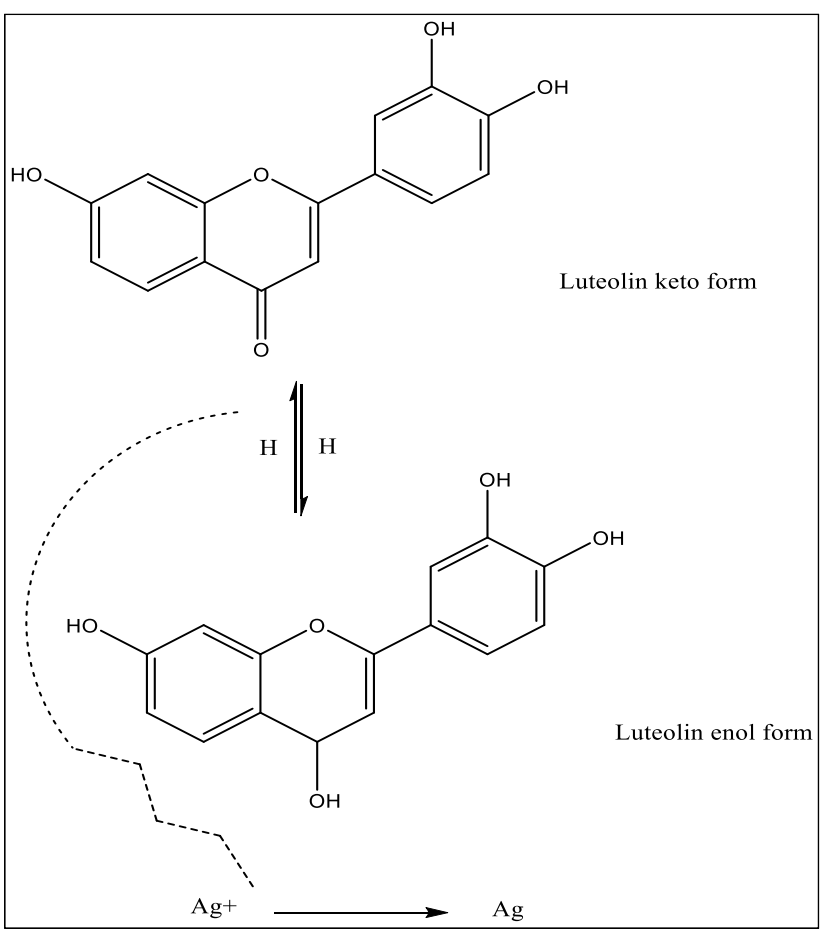

Fig. 7 Possible reaction mechanism of nanoparticles formation using plant extract.

\section{Applications}

For over centuries, silver-based compounds were used as nontoxic inorganic antibacterial agents due to their biocidal properties in many applications such as wood preservatives, water purification in hospitals, wound or bur healing. Silver ions and their related compounds have low toxicity towards animal cells but exhibit very high toxicity towards microorganisms like bacteria and fungi. Also, silver-based compounds are much cheaper than gold-based compounds. Also, it was observed that silver nanoparticles with $5 \mathrm{~nm}$ show the best antimicrobial efficacies and exhibit better antimicrobial property. Furthermore, silver in combination with some antibiotics increases the efficacy of the antibiotics. Nanoparticles are already used in numerous applications, including in vitro diagnosis. However, the use of nanoparticles in medicine is the prime focus of research are given below:

- Nanoparticles bound drugs to have an extended half lifetime in vivo, longer circulation times and can convey a high concentration of potent drug to the location where it is needed.

- The size of the drug nanoparticles and their surface characteristics can be modified to achieve the desired delivery characteristics.

- Nanoparticles bound drugs cannot be effectively circulated. Thus high localised circulation can be achieved.

- The $\mathrm{Fe}_{2} \mathrm{O}_{3}$ attached $\mathrm{Ag}$ nanoparticles can be used for water purification, and later, they can be removed using a magnetic field to avoid water contamination.

- The nano-crystalline silver dressing, gels, and creams effectively reduce bacterial infections in a chronic wound. In addition, the silver nanoparticles containing polyvinyl nano-fibres also show the efficient antibacterial property in wound dressing.

- Silver sulfadiazine depicts better healing of burn wounds due to its slow and steady reaction with serum and other body fluids.

- Silver impregnated medical devices like surgical masks and implanted devices show significant antimicrobial activities.

- Silver zeolite can be used in food preservation, disinfection, 
and decontamination of products.

- Silver nanoparticles can be used for water filtrations.

- Inorganic composites of nanoparticles can be used as a preservative in various products.

- Silver nanoparticles have been commonly found to have broad-spectrum activities against pathogens.

- Silver nanoparticles are larvicides against filariasis and malaria vectors.

- Silver nanoparticles have been shown to prevent HIV binding from hosting cells.

- Silver sulfadiazine is a combination of silver and sulfadiazine. Silver sulfadiazine is used as a broadspectrum antibiotic. All kinds of sulfa drugs have been tested in combination with silver.

However, sulfadiazine was found to be the most effective.

- Applications of AgNPs on catalysis: When silver nanoparticles are added into the reaction system, the chemical reaction speed gets altered. Thus, the nanocatalyst of silver nanoparticles has been a rapidly growing research area that involves the use of nanoparticles as a catalyst. We are pretty aware that metals like $\mathrm{Ag}, \mathrm{Au}, \mathrm{Pt}$, and other metal ions can catalyse the decomposition of $\mathrm{H}_{2} \mathrm{O}_{2}$ to oxygen.

- Silver nanoparticles have many other applications in various fields, such as nanoscale detection and solar cells.

- Silver nanoparticles and their complexes can be used for solar cells to enhance photoelectrical conversion efficiency and photovoltaic performances.

- The presence of silver nanoparticles increased unique Plasmon resonance optical scattering properties.

- Application of biogenic silver nanoparticles in wastewater treatment: An emerging technology for the abiotic degradation of recalcitrant compounds involves zerovalent metal or bimetallic nanoparticles. Zero valent metals have been used for reductive removal or transformation of organic compounds. In the area of water purification, nanotechnology offers the possibility of efficient removal of pollutants and germs.

\section{Recent Advances in Silver Nanoparticles}

Colloidal silver is the colloidal solution of silver nanoparticles suspended in a liquid. Physicians widely use this colloidal solution. Colloidal silver is marketed as alternative medicine. Colloidal silver products remain available in many countries as dietary supplements. Also, in homoeopathic medicine, Argentinum silver is used in different potencies. Silver nanoparticles can be incorporated in wound dressings. It has been observed that silver catheters and endotracheal breathing tubes may reduce the incidence of catheter-related urinary tract infections and ventilator-related pneumonia. The silver ion is bioactive and, in sufficient concentration, kills bacteria in vitro. Silver and silver nanoparticles are used as antimicrobial in various industrial, healthcare, and domestic applications.

\section{Hazardous Effects of silver and silver nanoparticles}

Although we have discussed the positive part of silver nanoparticles and nanotechnology so far, we tried to focus on the potential hazards of nanoparticles and nanotechnology. The principal admittance route is through ingestion, inhalation, dermal contact, and directly circulation through intravenous or intraperitoneal injection.

\subsection{Common but severe effects of silver nanoparticles}

- The adverse effects of free silver ions on human beings and animal cause's argyria, i.e. permanent bluish-grey discolouration of eyes.

- Exposure to soluble silver compounds may produce toxic effects like liver and kidney damage, eye, skin, respiratory tract irritation, and changes in blood cells.

- Silver ions cause changes in the permeability of cell membranes to potassium and sodium ions that affect ATP or mitochondrial activity.

- Nano-silver can induce toxic effects on proliferation and cytokine expression by peripheral blood mononuclear cells

- Nano-silver also shows severe toxic effects on male reproductive systems.

- Histological studies of nanoparticles over-exposed specimen reveal more substantial evidence of bile duct hyperplasia, with or without necrosis, fibrosis, and pigmentation in study animals.

- Studies reveal that the lungs and liver are primary target tissues for prolonged AgNPs exposures.

- Inhalation exposure studies reveal that the lung is an easy target for nanoparticles and that inhaled particles can reach the brain through nasopharyngeal systems.

- AgNPs caused cytotoxicity and dopamine depletion in neuroendocrine cells.

- AgNPs exposure results in disruption of hepatic cell cords and apoptotic changes.

- At low concentration, AgNPs stimulated vaso-relaxation.

- AgNPs induce blood-brain barrier destruction and neuronal degeneration. Subsequent studies demonstrated that the lungs and liver were primary target tissues.

- Studies over the years have proved that it is challenging to remove silver altogether if deposited in the body. However, animal and human studies have indicated that nano-silver can be excreted through hair, urine, and faeces materials. In addition, once orally administrated, silver nanoparticles pass through the liver, then into the bile, and are excreted through faeces.

- Researcher N. R. Prasad severely faced the problem of skin etching and hyperthermia. The disease continued for a longer time, even after specialised treatment. Prasad believes that one of the causes of the problem may be due to AgNPs.

Experiments using different nanoparticles have suggested that inhaled nanoparticles have very likely to be deposited in the olfactory mucosa of the nasopharyngeal region and subsequently be translocated into the brain via the olfactory 
nerve. The toxicological effects of silver nanoparticles are mentioned in Table 3, respectively.

\subsection{Biodistribution and toxicity of silver nanoparticles in mammalian models}

Human exposure to environmental materials may occur through various mechanisms such as inhalation, ingestion, and dermal contact. Systemic administration is also another possible route of entry. Tukenaka et al. studied ultrafine silver particles in Rattus rattus. It was observed that nanoparticle content in the lung decreased rapidly with the progress of time. Then, ultrafine silver nanoparticles were detected in the bloodstream, hepatic cells, kidney, and brain. Gastro-intestinal tract exposure may occur via accidental ingestion of contaminated food products. Significant hepatic changes in serum alkaline phosphate and cholesterol concentration were noted.

\subsection{Possible mechanism of silver induced toxicity}

The bacterial respiratory enzyme contains thiol (-SH) groups. Silver has an affinity with the thiol group. Thus it binds with the bacterial cell wall and cell membrane and inhibits the respiratory process.

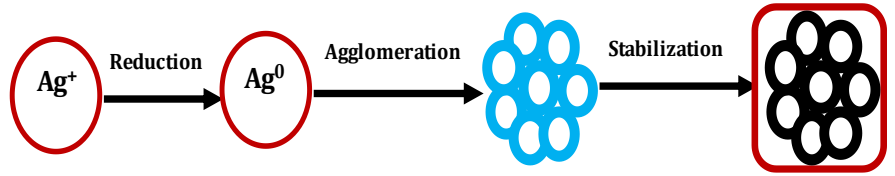

Fig. 8. Mechanism of action of silver ions.

\subsection{Mechanism of action of silver ions/ $\mathrm{AgNO}_{3}$}

The exact mechanism of the antibacterial effect of silver ions is not clearly understood. Literature survey reveals that a positive charge on silver ion may be responsible for its antimicrobial activity, and the mechanism was illustrated in Fig. 8 . The antibacterial activity may be derived through the electrostatic attraction between negatively charged cell membrane of microorganism and positively charged nanoparticles. Silver nanoparticles may attach to the cell membrane disturbing the permeability and respiration function of the cell. Smaller AgNPs have the larger surface area available for interaction, and thus it would give more bactericidal effect than the bigger one. It is also possible that silver nanoparticles may penetrate inside the cell. Some researchers believe that silver atom binds to thiol groups (-SH) of the enzyme, forming a stable S-Ag bond, and then it causes deactivation of enzymes in the cell membrane. Therefore,

Table 3. Toxicological effects on some cell.

\begin{tabular}{|c|c|c|c|}
\hline Cell line/ Organism & Dose & Duration of exposure & Observed Effects \\
\hline $\begin{array}{l}\text { In vitro Rattus rattus } \\
\text { spermatogonial stem cell line }\end{array}$ & $\mathrm{EC}_{50}: 8.75 \mu \mathrm{g} / \mathrm{ml}$ & 48 hours & $\begin{array}{l}\text { Reduced mitochondrial function } \\
\text { and increased membrane leakage. }\end{array}$ \\
\hline $\begin{array}{l}\text { Rattus rattus liver derived } \\
\text { cell line }\end{array}$ & $5-50 \mu \mathrm{g} / \mathrm{ml}$ & 24 hours & $\begin{array}{l}\text { Reduced mitochondrial level } \\
\text { potential, increase in reactive } \\
\text { oxygen species level. }\end{array}$ \\
\hline $\begin{array}{l}\text { Rattus rattus alveolar } \\
\text { macrophase }\end{array}$ & $10-75 \mu \mathrm{g} / \mathrm{ml}$ & 24 hours & Size dependent toxicity. \\
\hline $\begin{array}{l}\text { H1-1080 ( human fibro } \\
\text { sarcoma) and cells }\end{array}$ & $6.25-60 \mu \mathrm{g} / \mathrm{ml}$ & 24 hours & $\begin{array}{l}\text { Reduced cell visibility, DNA } \\
\text { fragmentation and higher } \\
\text { caspase- } 3 \text { activity. }\end{array}$ \\
\hline $\begin{array}{l}\text { Primary Rattus rattus } \\
\text { fibroblast and liver cell }\end{array}$ & $25-100 \mu \mathrm{g} / \mathrm{ml}$ & 24 hours & $\begin{array}{l}\text { Reduced cell visibility, oxidative } \\
\text { stress and apoptosis }\end{array}$ \\
\hline $\begin{array}{l}\text { Rattus rattus embryonic stem } \\
\text { cell and Rattus rattus } \\
\text { embryonic fibroblast }\end{array}$ & $50 \mu \mathrm{g} / \mathrm{ml}$ & 4-72 hours & $\begin{array}{l}\text { Induced DNA damage and } \\
\text { apoptosis. }\end{array}$ \\
\hline $\begin{array}{l}\text { Human mesenchymal stem } \\
\text { cells }\end{array}$ & $10 \mu \mathrm{g} / \mathrm{ml}$ & 24 hours & $\begin{array}{l}\text { Cyto- and genotoxic potential of } \\
\text { AgNPs in h MSC at significantly } \\
\text { higher concentration as compared } \\
\text { to antimicrobial effective levels. }\end{array}$ \\
\hline $\begin{array}{l}\text { NT2 human testicular } \\
\text { embryonic carcinoma cell } \\
\text { line and primary testicular } \\
\text { cells }\end{array}$ & $10-100 \mu \mathrm{g} / \mathrm{ml}$ & 24 hours & $\begin{array}{l}\text { Apoptosis, necrosis and } \\
\text { decreased proliferation in a } \\
\text { concentration and time dependent } \\
\text { manner. }\end{array}$ \\
\hline Human intestinal cell line & $4-48 \mu \mathrm{g} / \mathrm{ml}$ & 4-48 hours & $\begin{array}{l}\text { Induced decreasing adherence } \\
\text { capacity. }\end{array}$ \\
\hline Porcine skin & $0-1.7 \mu \mathrm{g} / \mathrm{ml}$ & 14 consecutive days & $\begin{array}{l}\text { Focal inflammation specifically } \\
\text { intracellular epidermal edema } \\
\text { after } 14 \text { days. }\end{array}$ \\
\hline
\end{tabular}


AgNPs as an antimicrobial agent has become promising candidates in the medical field in the present scenario.

When DNA molecules are in a relaxed state, the replication of DNA can be effectively conducted. However, when DNA is in condensed form, it loses its replication ability. When silver ion penetrates inside the bacterial cells, the DNA molecule turns into condensed forms and loses its replication ability leading to cell death. The heavy metals react with proteins by getting attached to thiol groups, and the proteins get deactivated. Silver nanoparticles exhibit good antimicrobial properties as compared with other salts due to their vast surface area. This large surface area provides better contact with microorganisms. The nanoparticles get attached to the cell membrane and also penetrate inside the bacteria. The nanoparticles release silver ions in the bacterial cells, which enhance bactericidal activities.

Reactive Oxygen Species (ROS) generation and Oxidative Stress appear to be two likely mechanisms for AgNPs toxicity. Oxidative stress occurs when the generation of ROS exceeds the capacity of the antioxidant defence mechanism. ROS and oxidative stress elicit various physiological and cellular events, including stress, inflammation, DNA damage, and apoptosis. Mitochondria is sensitive to AgNPs toxicity. Asharani et al. suggested that the disruption of the mitochondrial respiratory chain by AgNPs increased ROS production and interruption of ATP synthesis, thus leading to DNA damage.

\section{Conclusions}

Nature has elegant and ingenious ways of creating the most efficient miniaturised functional materials. So this nature's intelligence is exploited here in the use of plant extracts for making metallic nanoparticles which turn out to be inexpensive, easily scaled up, and environmentally benign. The synthesis of nanoparticles using plants is advantageous over other biological routes as maintaining cell culture can be avoided. There is significant variation in the chemical composition of plant extract of some species when it is collected from different parts of the world and may lead to different results. In medicine, nanoparticles are being used as antimicrobial agents in bandages. Applications in targeted drug delivery and clinical diagnostics are being developed. The plant extract acts as a reducing agent and capping agent. This is an easy, economical, and eco-friendly route for the synthesis of nanoparticles. This primary method is a novel and cost-effective method that excludes external stabilising or capping agents. The effects of various process variables like the concentration of the reductant, mixing ratio of precursor (silver nitrate) solution to plant extract, and interaction time for the formation of metal nanoparticles were studied. The antimicrobial activity of synthesised nanoparticles has been recorded against Gram-positive and Gram-negative bacterium A comparative study of antimicrobial activity against pathogenic bacteria is done concerning Penicillin. Also, the synergetic effect of nanoparticles and Penicillin is studied. Silver has always been an excellent antimicrobial and has been used for this purpose for ages. Though there are many mechanisms attributed to the antimicrobial activity shown by silver nanoparticles, the actual and most reliable mechanism is not fully understood or cannot be generalised as nanoparticles are found to act on different organisms in different ways.

The synthesised silver nanoparticles have been used for chemical transformations. The photocatalytic activity of nanoparticles for dye degradation has been well studied. The degradation phenomenon of Crystal Violet and Methylene blue dye has been studied. The concluding highlights of this research work can be mentioned as below:

- The plant extract acts as a reducing as well as a stabilising agent.

- The synthesised nanoparticles are primarily spherical and polydispersed.

- The use of plant extract in the green synthesis of nanoparticles is an easy, rapid, economical, and ecofriendly method of synthesis of nanoparticles.

- The synthesised nanoparticles are bio-compatible.

- Most of the synthesised nanoparticles are showing antimicrobial activities of different degrees.

- The reactions are taking place at room temperature without external energy.

\section{Future Directions}

- Noble metallic nanoparticles represent one of the fascinating developments in material chemistry in recent years. Silver nanoparticles are showing good antimicrobial activity against Bacillus subtilus bacterium. The prospect in this area is to study the possibility of finding its antimicrobial activities against other pathogenic bacteria.

- It is possible to carry out a comparative study of the disease curing effect of metallic nanoparticles synthesised by methods described in Ayurveda and the nanoparticles synthesised by the modern biological route of synthesis.

- Also, it is possible to separate various plant extract components by column chromatography and determine the exact component responsible for the synthesis of nanoparticles.

- It is possible to study cell-particle interaction and study the toxicity and bio-compatibility of synthesised nanoparticles.

- The future scope of the research includes drug delivery systems as nanocarriers.

- Even in dentistry, the AgNPs may be utilised in dental instruments band swathes and incorporated in orthodontic glues.

\section{Acknowledgement}

The authors pay sincere tribute to Late Ms Deepika Rai Dhirendra Prasad, who suddenly left this world and lived a brief life span. Her untimely departure has created an unrecoverable loss in the life of authors. The authors remember her on this occasion and pray Almighty God for the peace of her holy soul. 


\section{Conflict of interest}

There are no conflicts to declare.

\section{Supporting information}

Not Applicable.

\section{References}

[1] I. Amato, L. Carroll, Nanotechnology: shaping the world atom by atom. National Science and Technology Council, Committee on Technology, Interagency Working Group on Nanoscience, Engineering, and Technology (September 1999). Source: https://www.ewh.ieee.soc/cpmt/presentations/nanoarticle.pdf

[2] K. S. Siddiqi, A. Husen, R.A.K. Rao, J. Nanobiotechnol., 2018, 16, 1-28, doi: 10.1186/s12951-018-0334-5.

[3] H. Vahidi, F. Kobarfard, A. Alizadeh, M. Saravanan, H. Barabadi, Inorg. Chem. Commun., 2021, 124, 108385, doi: 10.1016/j.inoche.2020.108385

[4] H. Barabadi, M.A. Mahjoub, B. Tajani, A. Ahmadi, Y. Junejo, M. Saravanan., J. Clus. Sci., 30, 259-279, doi: 10.1007/s10876018-01491-7.

[5] K.M-Hung, X.H. Pham, J. Kim, S.H. Lee, H. Chang, W.Y. Rho, B.H. Jun, Int. J. Mol. Sci., 2020, 21, 5174; doi: 10.3390/ijms21145174.

[6] Z. Mingqian, S. Feng, L. Wang, Y. Zheng, Biotribology, 2016, 5, 31-43, doi: 10.1016/j.biotri.2015.08.002.

[7] B. Bhushan, Springer handbook of nanotechnology springer. 2017, Publisher: Springer-Verlag Berlin Heidelberg, $4^{\text {th }}$ edition, eBook ISBN 978-3-662-54357-3, doi: 10.1007/978-3-66254357-3.

[8] X. Li, J. Min. Metal. Mater. Soc., 2007, 59, 71-74, doi: 10.1007/s11837-007-0043-2.

[9] S. Mann, Biomimetic Materials Chemistry, Publisher: WileyVCH; 1st edition (1997), Hardcore, Pages. 400. ISBN: 978-0471-18597-0.

[10] A. Pradeep, P. Priyadharsini, G.J. Chandrasekaran, J. Magnet. Mag. Mater. $\quad 2010, \quad 320, \quad 2774-2779, \quad$ doi: 10.1016/j.jmmm.2008.06.012.

[11] O. Masala, R. Seshadri, R. Annu, Rev. Mater. Res., 2004, 34, 41-81, doi: 10.1146/annurev.matsci.34.052803.090949.

[12] K. Vemula, P. Aslam, U. Ajay Mallia, V. John, Chem. Mater., 2007, 19, 138-140, doi: 10.1021/cm062464n.

[13] H. Barabadi, H. Vahidi, K.D. Kamali, M. Rashedi, O. Hosseini, A.R.G. Ghomi, J. Clust. Sci., 31, 311-32, doi: 10.1007/s10876-019-01668-8.

[14] T. J. Park, K.G. Lee, S.Y. Lee, App. Microbiol. Biotechnol., 2015, 100, 521-534, doi: 10.1007/s00253-015-6904-7.

[15] P. Singh, Y.J Kim, D. Zhang, D.C. Yang, Trends Biotechnol., 2016, 34, 588-599, doi: 10.1016/j.tibtech.2016.02.006.

[16] Z. Molnar, V, Bodal, G. Szakacs, Sci. Rep., 2018, 8, 3943 3948, doi: 10.1038/s41598-018-22112-3.

[17] M. Sumper, E. Brunner, Adv. Fun. Mater., 2006 16, 17-26, doi: 10.1002/adfm.200500616.

[18] D. Bhattacharya, S. Gupta, Crit. Rev. Biotechnol., 2005, 25, 199-204, doi: 10.1080/07388550500361994.

[19] P. Jena, M. Bhattacharya, G. Bhattacharjee, B. Satpati, P.
Mukherjee, D Senapati, Nanoscale, 2020, 12, 3731-3749, doi: 10.1039/C9NR10700B.

[20] P. Velusamy, G.V. Kumar, V. J. Das, R. Pachaiappan, Toxicol. Res., 2016, 32, 95-102, doi: 10.5487/TR.2016.32.2.095.

[21] H. Barabadi, B. Tajani, M. Moradi, K.D. Kamali, R. Meena, S. Honary, J. Clust. Science, 30, 843-856, doi: 10.1007/s10876019-01554-3.

[22] X. Zhang, S. Yan, R.D. Tyagi, R.Y. Surampalli, Chemosphere, 2011, 82, 489-494, doi: 10.1016/j.chemosphere.2010.10.023.

[23] Singaravelu, G. Arockiamary, J. S. Kumar, V. G. Govindaraju, K. Coll. Surf. B: Biointerfaces, 2007, 7, 97-101, doi: 10.1016/j.colsurfb.2007.01.010.

[24] G. Ghomi, H. Vahidi, F. Kobarfard, A. Shah Reza, H. Barabadi, Iran. J. Pharm. Res., 2019, 8, 2101-2110, doi: 10.22037/ijpr.2019.112382.13722.

[25] H. Barabadi, Cell. Mol. Biol., 2017, 63, 3-5, doi: 10.14715/cmb/2017.63.12.2.

[26] T.C. Leung, Y. Wong, C. K. Xie, Mater. Chem. Phy., 2010, 121, 402-405, doi: 10.1016/j.matchemphys.2010.02.026.

[27] C.A. Mirkin, R.L. Letsinger, J.J. Storhoff., Nature, 1996, 382, 607-609, doi: 10.1038/382607a0.

[28] M. Oshima, T. Ariga, J. Biolog. Chem., 1975, 250, 69636968, doi: 10.1016/S0021-9258 (19)41026-0.

[29] X. Li, H. Xu, Chen, Z. S. Chen, J. Nanomaterials., 2011, 116, doi: 10.1155/2011/270974.

[30] S. Honary, H. Barabadi, P. Ebrahimi, F. Naghibi, A. Alizadeh, A, J. Nano. Res., 2015, 30, 106-115, doi: 10.4028/www.scientific.net/jnanor.30.106.

[31] K.B. Narayanan, A. Sakthivel, Adv. Colloid. Interf. Sci., 2010, 156, 1-13, doi: 10.1016/j.cis.2010.02.001.

[32] M. Rai, A. Yadav, A. Gade, Biotechnol. Adv., 2009, 27, 7683, doi: 10.1016/j.biotechadv.2008.09.002.

[33] K. Chaloupka, Y. Malam, A.M. Seifalian, Trends. Biotechnol., 2010, 28, 580-588, doi: 10.1016/j.tibtech.2010.07.006.

[34] N. Mokhtari, S. Daneshpajouh, S. Seyedbagheri, R. Atashdehghan, K. Abdi, S. Sarkar, S. Minaian, H. R. Shahverdi, A.R. Shahverdi, Mater. Res. bull., 2008, 44, 1415-1421, doi: 10.1016/j.materresbull.2008.11.021

[35] A. Singh, P.K. Gautam, A. Verma, V. Singh, P. M. Shivapriya, S. Shivalkar, A. K. Sahoo, S. K. Samanta, Biotechnol. Rep., 2020, 25, e00578, doi: 10.1016/j.btre.2020.e00427.

[36] A.B. Moghaddam, F. Namvar, M. Moniri, P. M. Tahir, S. Azizi, R. Mohamad, Molecules, 2015, 20, 16540-16565, doi: 10.3390/molecules200916540.

[37] G. Southam, T. J. Beveridge, Geochim. Cosmochim. Acta., 1994, 58, 4527-4530, doi:10.1016/0016-7037(94)90355-7.

[38] T. Klaus, R. Joerger, E. Olsson, C. Granqvist, Proc. Natl. Acad. Sci. $U \quad S \quad A . \quad 1999, \quad 96$, 13611-13614, doi: 10.1073/pnas.96.24.13611

[39] F. Ahmad, N. Ashraf, T. Ashraf, R.B. Zhou, D.C. Yin, Ppl. Microbiol. Biotechnol., 2019, 103, 2913-2935, doi: 10.1007/s00253-019-09675-5.

[40] S. S. Shankar, A. Rai, A. Ahmad, M. Sastry, J. Colloid 
Interface Sci., 2004, 15, 496-502, doi: 10.1016/j.jcis.2004.03.003. [63] A. Schrofel, G. Kratosova, I. Safarik, M. Safarikova, I. Raska, [41] S S. Shankar, A. A. M. Sastry, Biotechnol Prog., 2003, 19, L. M. Shor, Acta Biomater., 2014, 10, 4023-4042, doi: 1627-1631, doi: 10.1021/bp034070w.

[42] J.L. Gardea-Torresdey, J. G .Parsons, E. Gomez, J. PeraltaVidea, H.E. Troiani, P .Santiago, M. Jose Yacaman, Nano Lett., 2002, 2, 397-401, doi: 10.1021/n1015673+.

[43] J.L. Gardea-Torresdey, E. Gomez, J.R. Peralta-Videa, J. G. Troiani, M. Jose-Yacaman, Langmuir, 2003, 19, 1357-1361, doi: 10.1021/la020835i.

[44] R. Prasad, J. Nanopart., 2014, 1-8, doi: $10.1155 / 2014 / 96396$.

10.1016/j.actbio.2014.05.022.

[64] P. Jadhav, S. Shinde, S. S. Suryawanshi, S. B. Teli, P.S. Patil, A. A. Ramteke, N.G. Hiremath, N. R. Prasad, Eng. Sci., 2020, 12, 79-94, doi: 10.30919/es8d1138.

[65] S. Kumar, R. Amrutha, P. Arumugam, ACS Appl. Mater. Interfaces., 2011, 3, 1418-25, doi: 10.1021/am200443j.

[66] A.K. Jha, K.L. Prasad, Colloids Surf. B., 2010, 75, 330-334, doi: 10.1002/biot.200900221.

[67] G. Sigaravelu, J. Arockiamary, K. Ganesh, K. Govindraju, [45] J. Chidambaram, A. Rahuman, P. Perumal, Ind. Crop. Prod., 2013, 45, 423-429, doi: 10.1016/j.indcrop.2012.12.019

Colloids Surf. B., 2007, 57, 97-101, doi: 10.1016/j.colsurfb.2007.01.010.

[46] G. Sathishkumar, G. Chandrakasan, K. Karpagam, H. [68] X. JiampinG, Y.L. Jim, I.C.W. Danel, P.T. Yen, Small, 2007, Vedagiri, K. Premkumar, S. Sivaramakrishnan, Colloids Surf. B., 2012, 95, 235-40, doi: 10.1016/j.colsurfb.2012.03.001.

[47]. D. Sharma, S.Kanchi, S.K. Bisetty, Arab. J. Chem., 2019, 12, 3576-3600, doi: 10.1016/j.arabjc.2015.11.002.

[48] S.B. Aziz, Go.Hussein, M. A. Brza, S.J. Mohammed, R. T. Abdulwahid, S.R. Saeed, A.Hassanzadeh, Nanomaterials., 2019, 9, 1557, doi: 10.3390/nano9111557.

3, 672-682, doi: 10.1002/smll.200600612.

[69] T. Klaus, R. Joerger, E. Olsson, C.G. Granqvist, Proc. Natl. Acad. Sci., 1999, 96, 13611-13614, doi: 10.1073/pnas.96.24.13611.

[70] R.P. Parikh, B.L.V. Prasad, M.S. Patole, M. Sastry, Y.S. Shouche, Chembiochem, 2008, 9, 1415-1422, doi: 10.1002/cbic.200700592.

[49] H. Bahrulolum, S. Nooraei, N. Javanshir, J. Nanobiotechnol., [71] B. Nair, T. Pradeep, Crystal. Growth. Design., 2006, 2, 2932021, 19, 86, doi: 10.1186/s12951-021-00834-3.

[50] P. Khandel, R.K. Yadaw, D.K. Soni, J. Nanostruct. Chem., 2018, 8, 217-254, doi: 10.1007/s40097-018-0267-4.

298, doi: $10.1021 / \operatorname{cg} 0255164$.

[72] F. Maggy, M. Lengke, E. Fleet, G. Southam, Langmuir, 2007, 23, 2699, doi: 10.1021/la0613124.

[51] P. Dauthal, M. Mukhopadhyay, Ind. Eng. Chem. Res., 2012, [73] R.Y. Sweeney, C. Mao, X. Gao, A.M. Belcher, G. Geogiou, 51, 13014-13020, doi: 10.1021/ie300369g.

52] D. Mubarkali, N. Thajuddin, K. Jeganathan, M. Gunasegaram, Colloids Surf. B., 2011, 85, 360-366, doi: 10.1016/j.colsurfb.2011.03.009.

Chem. Biol., 2004, 11, 1553-1559, doi: 10.1016/j.chembiol.2004.08.022.

[53] M. Ahamed, S. Mohamad, M. Alsa, M.K.J. Siddiqui, Clin. Chim. Acta., 2010, 411, 1841-1848, doi: 10.1016/j.cca.2010.08.016.

[54] B. Harekrishna, D. K. Bhui, G. P. Sahoo, P. Sarkar, S. Pyne, A. Mishra, Colloids Surf, A. Physicochemical. Eng. Asp., 2009, 348, 212-216, doi: 10.1016/j.colsurfa.2009.07.021.

[55] N. Kaushik, M.S. Thakkar, S. Snehit, M.S. Mhatre, Y. Rasesh, M.S. Parikh, Nanomed. Nanotech, Biol. Med., 2010, 6, 257-262, doi: 10.1016/j.nano.2009.07.002.

[56] S. Shrivastava, T. Bera, S. K. Singh, G. Singh, P. Ramchandrarao, D. Dash, ACS Nano., 2009, 3, 1357-1364, doi: 10.1021/nn900277t CCC: \$40.75.

[57] B.N. Kannan, N. Sakthiivel, Adv. Collid. Interface. Sci., 2010, 156, 1-13, doi: 10.1016/j.cis.2010.02.001.

[58] S. Prabhu, E. K. Poulose, Int Nano Lett., 2012, 2, 32, doi: 10.1186/2228-5326-2-32.

[59] M. Arturo Lopez-Quintela, Colloid. Interface Sci., 2003, 8, 137-144, doi:10.1016/S1359-0294(03)00019-0.

[60] Y. Subba Rao, Venkata S. Kotakadi, T.N.V.K. Prasad, A.V. Reddy, Spectrochim. Acta A Mol. Biomol. Spectrosc., 2013, 103, 156-159, doi: 10.1016/j.saa.2012.11.028.

[61] R.K. Das, V. L. Pachapur, L. Lonappan, Nanotechnol. Environ. Eng., 2017, 2, 18, doi: 10.1007/s41204-017-0029-4.

[62] A. Shivaram, S. Bose, A. Bandopadhyay, Acta Biomater., 2017, 58, 550-560, doi: 10.1016/j.actbio.2017.05.048.

[74] D.P. Chuningham, L.L. Lundie LL, Appl. Environ. Microbio., 1993, 9, 7-14, doi: 10.1128/aem.59.1.7-14.1993.

[75] P. Malik, R. Shankar, V. Malik, N. Sharma, T. K. Mukherjee, 2014, 1-14, J. Nanopart., doi: 10.1155/2014/302429.

[76] Y. Konishi, K. Ohno, N.Saitoh S. Nagamine, Electrochima. Acta., 2007, 53, 186-192, doi: 10.1016/j.electacta.2007.02.073.

[77] H. Shiying, G. Zhirui, Y. Zhanga, S. Zhanga, J. Wanga, Mater Lett., 2007, 61, 3984-7, doi: 10.1016/j.matlet.2007.01.018. [78] D. Liangwei, J. Hong, L. Xiaohua, W. Erkang, Electrochem. Commun., 2007, 9, 1165-70, doi: 10.1016/j.elecom.2007.01.007. [79] A. Ahmad, S. Senapati, M. I. Khan, R. Kumar, M. Sastri M, Langmuir, 2003, 19, 3550-3, doi: 10.1021/la0267721.

[80] A. Ahmad, S. Senapati, V. Shrinivas, M. Sastry, Nanotechnology, 2003, 14, 824-8, doi:10.1088/09574484/14/7/323.

[81] A.R. Shahverdi, A. Fakhimi, H.R. Shahverdi, S. Minaian, Nanomedicine, 2007, 3, 168-71, doi: 10.1016/j.nano.2007.02.001. [82] M.I. Husseiney, M. Abd El-Aziz, M.A. Mahmoud, Spectrochemica. Acta. A., 2007, 67, 1003, doi: 10.1016/j.saa.2006.09.028.

[83] S. Jiang, H.G. Hur, Microbes Environ., 2013, 28, 312-315, doi:10.1264/jsme2.ME12149.

[84] M. Lengke, G. Southam, Geochim Cosmochim. Acta, 2006, 70, 3646, doi: 10.1016/j.gca.2006.04.018.

[85] J.H.P. Watson, D.C. Ellwood, A.K. Soper, J.M. Charnock, J. Magn. Magn. Mater, 1999, 203, 69-72, doi: 10.1016/S03048853(99)00191-2. 
[86] W. Hunter, D. Manter, Curr. Microbio., 2008, 57, 83, doi: 10.1007/s00284-008-9160-6.

[87] N. Pugazhenthiran, S. Anandan, G. Kathiravan, N.K.U. Prakash, S. Crawford, M. Ashokkumar, J. Nanopart. Res., 2009, 11, 1811, doi: 10.1007/s11051-009-9621-2.

[88] D.S A. Bazylinski, R. B. Frankel, B. Mann,J. W. King,P, L. Donaghay, A.K. Hanson, Appl. Environ. Microbiol., 1995, 61, 3232-3239, doi: 0099-2240/95/\$04.0010.

[89] S. Mann, N. C.H. Sparks, R. B. Frankel, D. Bazylinski, H. W Jannasch., Nature, 1990, 343, 6255, doi: 10.1038/343258a0.

[90] R. Ruwisch, J. Microbio. Methods, 1985, 4, 33-36, doi: 10.1016/0167-7012(85)90005-3.

[91] R.B. Frankel, G. Papaefthymiou, R. P. Blakemore, W. O’Brien, Biochim. Biophys. Acta. Mol. Cell. Res., 1983, 763, 147159, doi: 10.1016/0167-4889(83)90038-1.

[92] D. Bazylinski, R. Frankel, Nat. Rev. Microbiol.,2004, 2, $217-$ 230, doi: $10.1038 /$ nrmicro842.

[93] D. schüler, R.Uhl, E. Bäuerlein, FEMS Microbiol. Lett. 1995 132, 139-145, doi: 10.1111/j.1574-6968.1995.tb07823.x.

[94] T. M. Flynnn, D. A. Antonopoulos, K. A. Skinner, J. M. Brulc1, E. Johnston, M.I. Boyanov, M. Jae Kwon, K. M. Kemner, E.J. Loughlini, Plos One, 2021, 16, 1-23, doi: 10.1371/journal.pone.0251883.

[95] W. Bae, R. Abdullah, R. K. Mehra, Chemosphere, 1998, 37, 363-385, doi: 10.1016/S0045-6535(98)00051-4.

[96] J. D. Holmes, D.J. Richardson, S. Saed, R. E. Gowing, D. A. Russell, J.R. Sodeau, Microbiology, 1997, 143, 2521-2530, doi: 10.1099/00221287-143-8-2521.

[97] C. Mi, Y.Wang, J. Zhang, H. Huang, L. Xu, S. Wang, X. Fang, J. Fang, Chuanbin Mao,S. Xu, J. Biotechnol., 2011, 153, 125-132, doi: 10.1016/j.jbiotec.2011.03.014.

[98] M. Labrenz, J. F. Banfield, Micro. Ecol., 2004, 47, 205-17, doi:10.1007/s00248-003-1025-8

[99] M. Arshadi, S. M. Mousavi, P Rasoulnia, Waste. Manag., 2016, 57, 158-167, doi: 10.1016/j.wasman.2016.05.012.

[100] R.Y. Sweeney, C. Mao, X. Gao, J.L. Burt, A.M. Belcher, Chem. Bio., 2004, 11, 1553, doi: 10.1016/j.chembiol.2004.08.022. [101] M. Labrenz, G. K. Druschel, T. Thomson Ebert, S.A. Welch, Science, 2000, 290, 1744-1747,

10.1126/science.290.5497.1744.

doi:

[102] L. Wein, Z. Lin, P. Gu, J. Zhou, B. Yao, G. Chen, J. Nanopart. Res., 2009, 11, 279-288, doi: 10.1007/s11051-0089378-z.

[103] F.U. Mouxing, L.L. Quinghiao, S. Daohua, L.U. Yinghua, H.E. Ning, Chin. J. Chem. Eng., 2006, 14, 114, doi: 10.1016/S1004-9541(06)60046-3.

[104] A. R. Shahverdi, S. Minaeian, H.R. Shahverdi, H. Jamalifar, Pro. Biochem., 2007, 42, 919-923, doi: 10.1016/j.procbio.2007.02.005.

[105] H.S. Barud, C. Barrios, T. Regian, R.F.C. Marques, M. Verelst, M, Dexpert, Phys. J. Mat. Sci. Eng. C., 2008, 28, 515, doi: 10.1016/j.compositesa.2012.01.016.

[106] S.M. Baesman, T.D. Bullen, J. Dewald, D. Zhang, S. Curran, F.S. Islam, T.J. Beveridge R.S. Oremland, Appl. Environ. Microbiol., 2007 73, 2135-43, doi: 10.1128/AEM.02558-06.
[107] R. S. OremLand, M. J. Herbel, J. S. Blum, S. Langlley, T. J. Beveridge, P. M. Ajayan, Appl. Environ. Microbial, 2004, 70, 52, doi: 10.1128/aem.70.1.52-60.2004.

[108] S.M. Baesman, T.D. Bullen, J. Dewald, D. Zhang, S. Curran, F.S. Islam, Appl. Environ. Microbial., 2007, 73, 2135, doi: 10.1128/aem.02558-06.

[109] K. Prasad, A.K. Jha, A.R. Kulkarni, Nanoscale Res. Lett., 2007, 2, 248, doi: 10.1007/s11671-007-9060-x.

[110] M.F. Lengke, M.E. Fleet, G. Southam, Langmuir, 2006, 22, 7318, doi: 10.1021/la060873s.

[111] S. M Baesman, T. D. Bullen, J. Dewald, D. Zhang, S. Curran, F. S. Islam, T. J Beveridge, R. S. Oremland, Appl. Environ. Microbiol., 2007, 73, 2135-2143, doi: 10.1128/AEM.02558-06.

[112] Y. Roh, R.J. Lauf, A.D. McMillan, C.J. Rawn C, Zang, J. Bai, Solid. State. Commun., 2001, 118, 529-534, https://doi.org/10.1016/S0038-1098(01)00146-6.

[113] A. Bharde, Y, Wani, P.A. Shouche, B.L.V. Prasad, M. Sastry, J. Am. Chem. Soc., 2005, 127, 9326. doi: 10.1021/ja0508469.

[114] S. Shankar, A. Rai, M. Sastry, Biotech. Prog., 2003, 19, 1627-31, doi: 10.1021/bp034070w.

[115] S. Shankar, Rai A, B. Ankamwar, A. Ahmad, M. Sastry, Nat. Mater., 2004, 3, 482-8, doi: 10.1038/nmat1152.

[116] V. Armendariz, I, Herrera, J.R. Peralta-Videa, M. JoseYaman, H. Troiani, P. Santiago, J.L. Gardea-Torresdey, J. Nanopart. Res., 2004, 6, 377-382, doi: 10.1007/s11051-0040741-4.

[117] H. Jiale, L. Qingbiao, S. Daohua, L. Yinghua, Su, Yuanbo, Y. Xin, Nanotechnology, 2007, 18, 105104-105115, doi:10.1088/0957-4484/18/10/105104.

[118] J. Huang, L. Liqin,L. Qingbiao, D. Sun, Y. Wang, Y. Lu, N. He' K. Yang, X. Yang, H. Wang, W. Wang, Ind. Eng. Chem. Res., 2008, 47, 6081-6090, doi: 10.1021/ie701698e.

[119] U.B. Jagtap, V.A. Bapat, Ind. Crop. Prod., 2013, 46, 132137, doi: 10.1016/j.indcrop.2013.01.019.

[120] H. Bar, D. Kr Bhui, G.P. Sahoo, P. Sarkar, A. Mishra, Colloids Surf, A. Physicochemical. Eng. Asp., 2009, 339, 134-139, doi: 10.1016/j.colsurfa.2009.02.008.

[121] J.C. Chen, Z.H. Lin, X.X. Ma, Lett. Appl. Microbiol., 2003, 37, 105-108, doi:10.1046/j.1472-765X.2003.01348.x.

[122] A. Ahmad, P. Mukharji, S. Senapati, D. Mandal, M.I. Khan, R. Kumar, M. Sastry, Colloids Surf. B., 2003, 28, 313-8, doi: 10.1016/S0927-7765(02)00174-1.

[123] J.R. Nakkala, R. Mata, K. Gupta, R. Sadras, Eur. J. Med. Chem., 2014, 85, 784-94, doi: 10.1016/j.ejmech.2014.08.024.

[124] J.R. Nakkala, R. Mata, A.K. Gupta, Ind. Crop. Prod., 20154, 52, 562-6, doi: 10.1016/j.indcrop.2013.10.050.

[125] Q. Suna, X. Cai, J. Li, M. Zheng, Z. Chenb, C.P. Yui, Colloids Surf, A. Physicochemical. Eng. Asp., 2014, 444, 226-31, doi: 10.1016/j.colsurfa.2013.12.065.

[126] A. Nabikhan, K. Kandasamy, A. Raj, N.M. Alikunhi, Colloids Surf. B., 2010, 79, 488-493, doi: 10.1016/j.colsurfb.2010.05.018.

[127] R. Mariselvam, A.J.A. Ranjitsingh, U. Raja, A. Nanthini, K. Kalirajan, C. Padmalatha, M.P. Sevalkumar, Spectrochim. Acta A Mol. Biomol. Spectrosc., 2014, 129, 537-541, doi: 
10.1016/j.saa.2014.03.066.

[128] R. Mata, J.R. Nakkala, S.R. Sadras, Colloids Surf. B., 2015, 128, 276-286, doi: 10.1016/j.colsurfb.2015.01.052.

[129] B. Sadeghi, F. Gholamhoseinpoor, Spectrochim. Acta A Mol. Biomol. Spectrosc., 2015, 134, 310-315, doi: 10.1016/j.saa.2014.06.046.

[130] B. Sadeghi, A. Rostami, S.S, Spectrochim. Acta A Mol. Biomol. Spectrosc., 2015, 134, 326-332, doi: 10.1016/j.saa.2014.05.078.

[131] B. Ulug, M.H. Turkdemir, A. Cicek, A. Mete, Spectrochim. Acta A Mol. Biomol. Spectrosc., 2015, 135, 153-161, doi: 10.1016/j.saa.2014.06.142.

[132] S. Monaliben, G.E.J. Poinern, D. Fawcett, Int. J. Res. Med. Sci., 2016, 4, 2886-2892, doi: 10.18203/23206012.ijrms20161971

[133] S.A. Masurkar, V.B. Shidore, S.P. Kamble, Nano. Micro. Lett., 2011, 3, 189-194, doi: 10.3786/nml.v3i3.p189-194.

[134] S. Kumar, R. M. Daimary, M. Swargiary, A, Brahma, S. Kumar, M. Ukesh Singh, Int. J. Pharm. Bio. Sci., 2013, 4, 378384.

[135] N. H. Mohamed, M. AhmedIsmail, W. M.Mageed, Ahmed A. M. Shoreit., Asian. Pac. J. Trop. Biomed., 2014, 4, 876-883, doi: 10.12980/APJTB.4.201414B216.

[136] P. Logeswari, S. Silambarasan, J. Abraham, Sientia. Iranica, F., 2013, 20, 049-1054, doi: 10.1016/j.scient.2013.05.016.

[137] A. Paulke, C. Kremer, C. Wunde., Anal. Bioanal. Chem., 2021, 404, 531-538, doi: 10.1007/s00216-012-6121-5.

[138] C. S. Truong, E. SeO, H. Sook., Oxid. Med. Cell. Longev., 2019, 1-14, 4310319, doi: 10.1155/2019/4310319.

[139] K. B. Narayanan, H. Ho Park, European. J. Plant. Pathol., 2014, 140, 23-45, doi: 10.1007/s10658-014-0399-4.

[140] K.B. Narayanan, H.H. Park, Eur, J. Plant. Pathol., 2014, 140, 185-92. doi:10.1007/s10658-014-0399-4.

[141] S.P. Patil, S.T. Kumbhar, Future. J. Pharm. Sci., 2020, 6 , 90-96, doi: 10.1186/s43094-020-00111-4.

[142] M. Zarga, A.A. Hamid, F.A. Bakar, M.N. ShamsudiN, K. Shamelik, F. Jahanshiri, Molecules, 2011, 16, 6667-6676, doi: 10.3390/molecules 16086667.

[143] V. Kathiravan, S. Ravi, S.A. Kumar, Spectrochim. Acta A Mol. Biomol. Spectrosc., 2014, 130, 116-121, doi: 10.1016/j.saa.2014.03.107.

[144] M.J. Firdouse, P. Lalitha, Asian J. Pharma, Clin. Res., 2012, 6, 92-94.

[145] N.N. Rupiasiah, A. Aher, S. Gosavi, P.B. Vidyasagar, J. Phys. Conf, Ser., 2013, 423, 1-8, doi: 10.1088/17426596/423/1/012032.

[146] K. Vijayraghavan, S. Nalini, N.U. Prakash, D. Madhankumar, Colloids Surf. B., 2012, 94, 144-147, doi: 10.1016/j.colsurfb.2012.01.026.

[147] S. Mondal, N. Roy, R.A. Laskar, S. Basu, D. Mandal, N. Arabegaum, Colloids Surf. B., 2011, 82, 497-504, doi: 10.1016/j.colsurfb.2010.10.007.

[148] A. Bankar, B. Joshi, A.R Kumar, S. Zinjarde S Colloids Surf, A. Physicochemical. Eng. Asp., 2010, 368, 58-63, doi: 10.1016/j.colsurfa.2010.07.024.
[149] T.N.V.K.V. Prasad, E. Elumanai, Asian. Pac. J. Trop. Biomed., 2011, 1, 439-42, doi: 10.1016/S2221-1691(11)60096-8. [150] K.M.K.G. Perera, K.A.S.S. Kuruppu, A.M.R. Chamara, SN. Appl. Sci., 2020, 2, 1974, doi: 10.1007/s42452-020-03640-y.

[151] G. Rajakumar, A. Abdul Rahuman, Acta. Trop., 2011, 118, 196-203, doi: 10.1016/j.actatropica.2011.03.003.

[152] T. Santhoshkumar, A.A., Rahuman, G. Rajkumar, S. Marimuthu, A. Bagvan, C. Jayaseelan, A. A. Zahir, G. Elango, C. Kamaraj., Parasitol Res., 2011, 108, 693-702, doi: 10.1007/s00436-010-2115-4.

[153] C. Krishnaraj, E. Jagan, S. Rajasekar, P. Sevalkumar, P. Laichelvan, N. Mohan, Colloids Surf. B., 2010, 76, 50-54, doi: 10.1016/j.colsurfb.2009.10.008.

[154] M. Ahmed, M.A.M. Khan, M.K.J. Siddiqui, M.S. AlSalhi, S.A. Altrokayan, Physica E: Low-Dimens.Syst. Nanostructures., 2011, 43, 1266-1271, doi: 10.1016/j.physe.2011.02.014.

[155] S.P. Chandran, M. Chaudhary, R. Pasricha, A. Ahmed, M. Sastry, Biotech. Prog., 2006, 22, 577-83, doi: 10.1021/bp0501423. [156] S. Kaviya, J. Santhanalakshmi, B. Viswanathan, J. Muthumary, K. Srinivasan, Spectrochim. Acta A Mol. Biomol. Spectrosc., 2011, 79, 594-598, doi: 10.1016/j.saa.2011.03.040

[157] M. J. Sila, M. I. Nyambura, D. A. Abong, F. B. Mwaura, E. Iwuoha., Nano. Hybr. Comp., 2019, 25, 32-45, doi: 10.4028/www.scientific.net/NHC.25.32.

[158] T. Elavazhagan, K.D. Arunachalam, Int. J. Nanomedicine., 2011, 6, 1265-78, doi: 10.2147/IJN.S18347.

[159] G. Premanand, N. Shanmugam, N. Kannadasan, Appl. Nanosci., 2016, 6, 409-415, doi:10.1007/s13204-015-0442-6.

[160] J, Kesharwani, K.Y, Yoon, J. Hwang, M Rai, J. Bionanosci., 2009, 3, 39-44, doi:10.1166/jbns.2009.1008.

[161] S.P. Singh, A. Mishra, R. K. Shyanti, Biol. Trace. lem. Res., 2021, 199, 1316-1331, doi: 10.1007/s12011-020-02255-z.

[162] S. Ahmed, M. Ahmad, B. L. Swami, S. Ikram, J. Adv. Res., 2016, 7, 17-28, doi: 10.1016/j.jare.2015.02.007.

[163] X. Yang, Q. Li, H. Wang, J. Huang, L. Lin, W. Wang, J. Nanopart. Res., 2010, 12, 1589-98, doi: 10.1007/s11051-0099675-1.

[164] A. Jegadeeshwari, N. Dharathi, V. Lakshmi, V. Kumari, N. Gandhi, Asian J. Pharm. Clin. Res., 2017, 10, 31-37, doi: 10.22159/ajpcr.2017.v10i7.18439

[165] A. K. Mittal, Y. Chisti, Uttam C. Banerjee, Biotechnol. Adv., 2013, 31, 346-356, doi: 10.1016/j.biotechadv.2013.01.003.

[166] M. Sathishkumar, K. Sneha, I.S. Kwak, J. Mao, S. Tripathy, Y.S. Yun, J. Hazard. Mater., 2009, 171, 400-404, doi: 10.1016/j.jhazmat.2009.06.014

[167] B. Ankamwar, C. Damle, A. Ahmad, M. Sastry., J Nanosci. Nanotechnol., 2005, 5, 1665-1671. doi: 10.1166/jnn.2005.184.

[168] R. Veerasamy, T. ZiXin, S. Gunasagaran, T. Foo, W. Xiang, E. Fang, C. Yang, N. Jeyakumar, S. Arumugam Dhanaraj J. Saudi Chem. Soc., 2011, 15, 113-120, doi: 10.1016/j.jscs.2010.06.004.

[169] M. Vivek, P.S. Kumar, S. Steffi, S. Sudha, Avicenna. J. Med. Biotechnol, 2011, 3, 143-148,

[170] S.S. Shankar, A. Ahmad, M.N. Sastry, Biotech. Prog, 2013, 19, 1627-1631, doi: 10.1021/bp034070w.

[171] D.M. Ali, N. Thajuddin, K. Jeganathan, M. Gunasekaran, 
Colloids Surf. B., 2011, 85, 360-365, doi: Author information

10.1016/j.colsurfb.2011.03.009.

[172] S. Arulkumar, M. Sabean, Int. J. Res. Pharm. Sci., 2010, 1, 417-420. ISSN: 0975-7538

[173] A.K. Mittal, A. Kaler, U.C. Banerjee, Nano. Bio-Med. Eng., 2012, 4, 118-124, doi: 10.5101/nbe.v4i3.p118-124.

[174] S.P. Dubey, M. Lehtinen, M. Sillanpaa, Process. Biochem., 2010, 45, 1065-1071, doi: 10.1016/j.procbio.2010.03.024.

[175] P. Mukharjee, A. Ahmad, D. Mandal, S. Senapati, M.I. Khan, R. Parishcha, P. V. Ajaykumar, M. Alam, R. Kumar, M. Sastry, Nano Lett., 2001, 1, 515-519, doi: 10.1021/n10155274.

[176] K.C. Bhainsa, S.F. D’Souza, Colloids Surf. B., 2006, 47, 160-164, doi: 10.1016/j.colsurfb.2005.11.026.

[177] P. Mukharjee, M. Roy, B. Mandal, G. Dey, P. Mukherjee P, Ghatak, J. Nanotechnology., 2008, 19, 75103-75110, doi: 10.1088/0957-4484/19/7/075103.

[178] P. Mukherjee, A. Ahmad, D. Mandal, S. Senapati, S. R. Sainkar, M.I. Khan, R. Parishcha, P. V. Ajaykumar, M. Alam, R. Kumar, M. Sastry., Nano Lett., 2001, 1, 515-519, doi: 10.1021/nl0155274.

[179] A. Bharde, D. Rautaray, V. Bansal, A. Ahmad, S.M. Yusuf, M. Sanyal, M. Sastry, Small, 2006, 2, 135-4, doi: 10.1002/smll.200500180.

[180] C.T. Dameron, R.N. Reese, R.K. Mehra, A.R. Kortan, P.J. Caroll, M.L. Steigerwald, Nature, 2006, 338, 596-597, doi: 10.1038/338596a0

[181] M. Kowshik, S. Ashtaputre, S. Kharrazi, W. Vogel, J. Urban, S. Kulkarni, K. Paknikar, Nanotechnology, 2002, 14, 95-101, doi: 10.1088/0957-4484/14/1/321.

[182] M. Stephen, Nature, 1993, 365, 499-506, doi: 10.1038/365499a0.

[183] A. M. Fayaz, K. Balaji, M. Girilal, R. Yadav, P. T.Kalaichelvan, R. Venketesan, Nanomed.: Nanotechnol. Bio. Med., 2010, 6, 103-109, doi: 10.1016/j.nano.2009.04.006.

[184] A. Ingle, M. Rai, A. Gade, M. Bawaskar, J. Nanopart. Res., 2009, 11, 2079-2087, doi: 10.1007/s11051-008-9573-y.

[185] S. Basavraja, S.D. Balaji, A. Lagashetty, A.H. Rajasab, A. Venkatraman, Mat. Res. Bull, 2008, 43, 1164-1170, doi: 10.1016/j.materresbull.2007.06.020.

[186] K. B. Narayanan, N. Sakthivel, Adv. Colloid Interface Sci., 2010, 156, 1-13, doi: 10.1016/j.cis.2010.02.001.

[187] G.M. Nazeruddin, N.R. Prasad, S.R. Waghmare, K.M. Garadkar, I.S. Mulla, J. Alloys Comp., 2014, 583, 272-277, doi: $0.26479 / 2016.0204 .02$.

[188] H. F. Zhang, X. H. Yang, Y. Wang, Trends. Food. Sci. Techno., 2011, 22, 672-688, doi: 10.1016/j.tifs.2011.07.003.

[189] Q. H. Tran, V. Q. Nguyen, A.T. Le, Adv. Nat. Sci. Nanosci. Nanotechnol., 2013, 4, 033001, doi:10.1088/issn.2043-6262.

Publisher's Note: Engineered Science Publisher remains neutral with regard to jurisdictional claims in published maps and institutional affiliations.

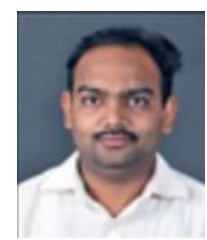

Dr. Saurabh Rai Dhirendra Prasad is working as Assistant Professor at DKTE Society's Textile and Engineering Institute, Ichalkaranji and also research scholar of Shivaji University, Kolhapur. He has qualified M.E. in Electronics and Telecommunication from KIT College of Engineering, PhD from Shivaji University Kolhapur. He has published several papers in journal of repute. He has also worked as reviewer for various international journals. He has about 16 years of teaching experience. He has expertise in the field of microwave engineering, audio and video engineering and digital signal processing.

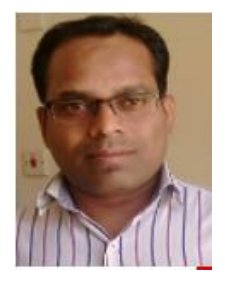

Dr. Shivanand B. Teli currently working as Assistant Professor (PG) at Department of Industrial Chemistry, Shivaji University, Kolhapur, INDIA He joined as Doctorate Student in Jan 2004 in same department and same university and received his doctorate degree in September 2007. He worked as a Research Associate (RA) in Indian Institute of Technology (IIT), Kanpur INDIA. He received a post doctorate offer from Seoul National University, South Korea in 2008. He also awarded as Brain Korea Fellowship and joined, Hanyang University Seoul, South Korea (2009). He works 3 years as a Marie Curie Research Fellow at IMDEA water (Madrid), Spain and finally completed 2.5 years post doctorate position from Qatar University, Qatar. His primary research synthesis of membranes for water desalination. He has 16 years knowledge on various membrane process such RO, UF, MF, $P V, N F$ and MD etc. He holds near about 3.5 years of teaching experience on master degree course.

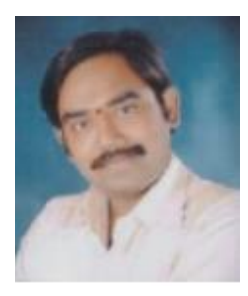

Dr. Neeraj Rai Dhirendra Prasad has completed master's degree in chemistry from Shivaji University, Kolhapur. Then, he completed PhD in chemistry from SPPU, Pune. He has written several research papers in the journal of inter-national repute. Presently, he is trying to implement concept of nanotechnology in veterinary medicine and human medicine. He is interested in paranormal phenomenon and trying to connect to modern science. 